\title{
DEPOSITION TANK CORROSION TESTING FOR ENHANCED CHEMICAL CLEANING - POST OXALIC ACID DESTRUCTION
}

\author{
John I. Mickalonis
}

AUGUST 2011

Savannah River National Laboratory

Savannah River Nuclear Solutions

Aiken, SC 29808

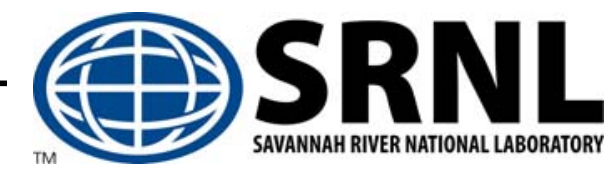




\section{DISCLAIMER}

This work was prepared under an agreement with and funded by the U.S. Government. Neither the U. S. Government or its employees, nor any of its contractors, subcontractors or their employees, makes any express or implied:

1. warranty or assumes any legal liability for the accuracy, completeness, or for the use or results of such use of any information, product, or process disclosed; or

2. representation that such use or results of such use would not infringe privately owned rights; or

3. endorsement or recommendation of any specifically identified commercial product, process, or service.

Any views and opinions of authors expressed in this work do not necessarily state or reflect those of the United States Government, or its contractors, or subcontractors.

Printed in the United States of America

Prepared for

U.S. Department of Energy 
Key Words:

Sludge Dissolution

Sludge Simulant

Tank Cleaning

Oxalic Acid

Corrosion

Retention:

Permanent

\title{
DEPOSITION TANK CORROSION TESTING FOR ENHANCED CHEMICAL CLEANING - POST OXALIC ACID DESTRUCTION
}

\author{
John I. Mickalonis
}

AUGUST 2011

Savannah River National Laboratory

Savannah River Nuclear Solutions

Savannah River Site

Aiken, SC 29808 
SRNL-STI-2011-00428, REVISION 0

\section{REVIEWS AND APPROVALS}

J. I. Mickalonis, Author, Material Performance \& Corrosion Technology

Date

B. Garcia-Diaz, Technical Review, Material Performance \& Corrosion Technology Date

K. E. Zeigler, Level 4 Manager, Material Performance \& Corrosion Technology Date

F. M. Pennebaker, E\&CPT Research Programs

Date

P. E. Carroll, Chemical Cleaning Engineering, Savannah River Remediation

Date

E. T. Ketusky, Closure Project Engineering, Savannah River Remediation

Date

R. H. Spires, Waste Removal and Tank Closure, Savannah River Remediation

Date

- ii - 


\section{TABLE OF CONTENTS}

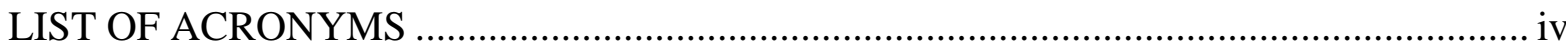

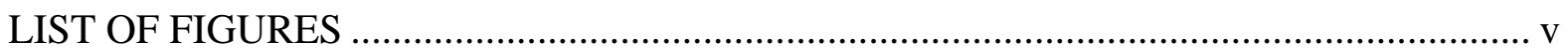

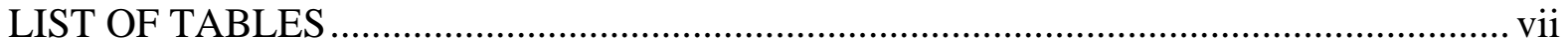

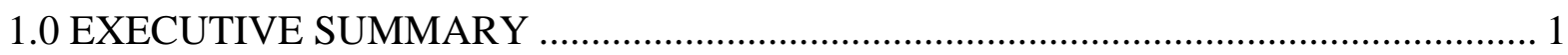

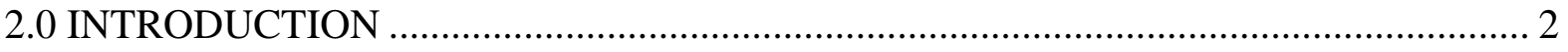

3.0 EXPERIMENTAL PLAN AND PROCEDURE .................................................. 2

3.1 Corrosion Test Techniques, Procedures and Equipment ............................................. 3

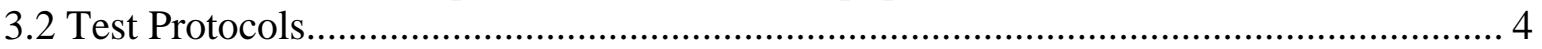

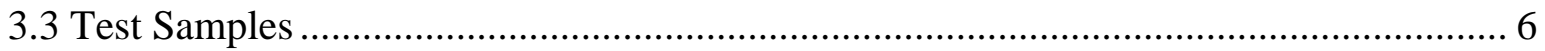

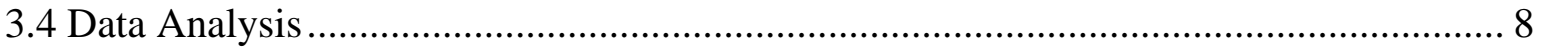

3.5 Technical Data Quality to Support Safety Class Functional Classification .................. 9

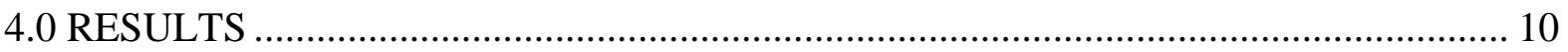

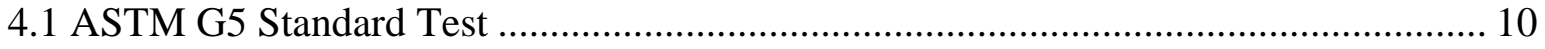

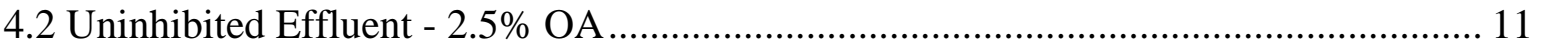

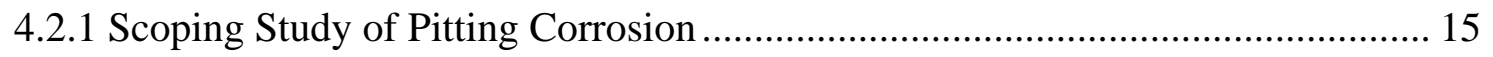

4.3 Uninhibited Effluent - 1\% OA.......................................................................... 15

4.4 Effluent Under Corrosion Control - 2.5\% OA......................................................... 20

4.4.1 F-Area Sludge with Supernate or Hydroxide and No Evaporation ..................... 20

4.4.2 H-Area Sludge with Supernate or Hydroxide and No Evaporation ..................... 23

4.4.3 F-Area Sludge with Evaporation ................................................................. 25

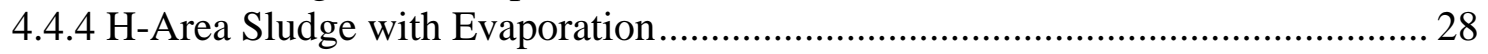

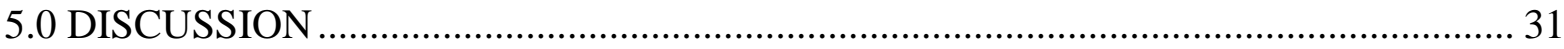

5.1 Impacts on General Corrosion Rate of Deposition Tanks ........................................ 31

5.2 Impacts on Corrosion Process of Deposition Tanks ................................................ 33

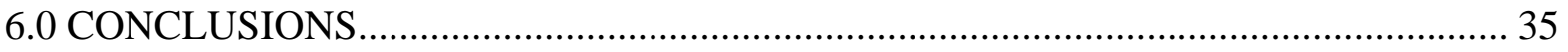

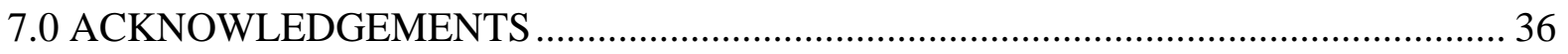

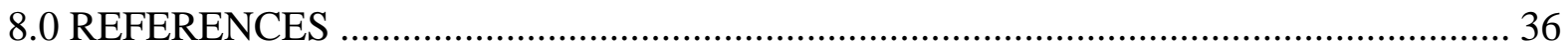

APPENDIX I. Weight Losses and Corrosin Rates of Immersion Coupons ......................... 39

APPENDIX II Instantaneous Corrosion Rates of Electrochemical Coupons ....................... 40

APPENDIX III Instantaneous Corrosion Rates of Electrochemical Coupons In Effluent

Treated for Corrosion Control 


\section{LIST OF ACRONYMS}

AOP Advanced Oxidation Process

ASTM ASTM International

A537 ASTM A537 Low Carbon Steel

CPP Cyclic Potentiodynamic Polarization

ECC Enhanced Chemical Cleaningt

HLW High Level Waste

HM H-Modified

HST Hazardous Simulant Testing

LPR Linear Polarization Resistance

MS\&T Materials Science and Technology

M\&TE Measurement \& Testing Equipment

PAR Princeton Applied Research

OA Oxalic Acid

OCP Open-Circuit Potential

PUREX Plutonium and Uranium Recovery by EXtraction

SRNL Savannah River National Laboratory

SRR Savannah River Remediation

SRS Savannah River Site

TTQAP Task Technical and Quality Assurance Plan

UV Ultraviolet

304L Type 304L Stainless Steel 


\section{LIST OF FIGURES}

Figure 3.1-1 Corrosion test cell for testing in uninhibited effluent from the destruction loop

Figure 3.3-1 Mounted electrochemical coupon in sample holder for ECC-HST ............. 7

Figure 4.1-1 Potentiodynamic scans performed according to ASTM G5 for potentiostats used during ECC-HST corrosion testing ................................................ 10

Figure 4.2-1 A537 (A) and 304L (B) immersion coupons after exposure in uninhibited effluent from decomposition of 2.5\% OA dissolved F-area sludge............ 11

Figure 4.2-2 Stereomicroscope photograph (20x) of coupon A537CL1-51 after exposure in uninhibited effluent from decomposition of 2.5\% OA dissolved F-area sludge ............................................................................................ 12

Figure 4.2-3 Metallograph of microstructure associated with coupon A537CL1-51...... 12

Figure 4.2-4 Stereomicroscope photograph (10x) of coupons EC-A537-39 (A) and ECA537-41 (B) after electrochemical testing in uninhibited effluent from decomposition of $2.5 \%$ OA dissolved F-area and H-area sludge, respectively 13

Figure 4.2-5 CPP scans for coupons EC-A537-39 and EC-A537-41 in effluent from decomposition of $2.5 \%$ OA dissolved F-area and $\mathrm{H}$-area sludge, respectively

Figure 4.3-1 Immersion coupons exposed to uninhibited effluent from decomposition of $1 \%$ OA dissolved F-area sludge and no UV light during destruction: (A) A537CL1-33 and (B) 304L-01 …............................................................. 16

Figure 4.3-2 Immersion coupons exposed to uninhibited effluent from decomposition of $1 \%$ OA dissolved H-area sludge and no UV light during destruction: (A) A537CL1-40 and (B) 304L-07 16

Figure 4.3-3 Photographs of immersion coupon, A537CL1-35, exposed to uninhibited effluent from decomposition of $1 \%$ OA dissolved F-area sludge and using a clean UV light: (A) as-received; (B) as-cleaned; (C) 10x stereomicroscope view.

Figure 4.3-4 CPP scans from Batch 1 in uninhibited effluent from the destruction loop with clean and no light conditions using F-area and $\mathrm{H}$-area sludge dissolved by $1 \%$ OA. Arrows indicate direction of scan . 19

Figure 4.4.1-1 Corrosion coupons - Case 1A - low magnification: (A) electrochemical, EC-A537-16 and (B and C) immersion, A537CL1-53, front and back....... 20

Figure 4.4.1-2 Corrosion coupons - Case 1A - high magnification: (A) electrochemical, EC-A537-16 and (B) immersion, A537CL1-53 ..................................... 21

Figure 4.4.1-3 CPP scans for coupons EC-A537-16 and EC-A537-17 (Case 1A) ............ 22

Figure 4.4.2-1 Corrosion coupons - Case 2A - low magnification: (A) electrochemical, EC-A537-23 and (B and C) immersion, A537CL1-60, front and back....... 23

Figure 4.4.2-2 Corrosion morphology for Case 2A coupons: (A) immersion coupon A537CL1-60 showing localized breakdown, 60X; (B) electrochemical, ECA537-23, tiny pits across surface. 
Figure 4.4.2-3 CPP scans for coupons EC-A537-22 (Case 2A), EC-A537-24 (Case 2B) and EC-A537-26 (Case 4) 25

Figure 4.4.3-1 Corrosion coupons - Case 5: (A) electrochemical, EC-A537-28; (B and C) immersion coupon, A537CL1-65, front and back 26

Figure 4.4.3-2 Corrosion morphology for cases 5 and 7 coupons: (A) electrochemical coupon, EC-A537-30, case 7; (B) immersion coupon, A537CL-66, case 5; and (C) immersion coupons, A537CL1-65, case 5...................................... 26

Figure 4.4.3-3 CPP scans for coupons EC-A537-30 and EC-A537-31 (Case 7). .............. 27

Figure 4.4.4-1 Corrosion coupons - Case 8: (A) electrochemical, EC-A537-37; (B and C) immersion coupon, A537CL1-02, front and back ………………………... 29

Figure 4.4.4-2 Corrosion morphology for case 6 coupons: (A) electrochemical coupon, ECA537-32 and (B) immersion coupon, A537CL-69 ………………………... 29

Figure 4.4.4-3 CPP scans for coupons EC-A537-34 (case 8) and EC-A537-38 (case 6). Reverse portion of the scan has been truncated for clarity.......................... 30

Figure 5.2-1 Iron-Oxalic Acid-Water Pourbaix Diagram [16] ......................................... 35 


\section{LIST OF TABLES}

Table 3.2-1 Corrosion Test Protocol During ECC-HST For Uninhibited Destruction Loop

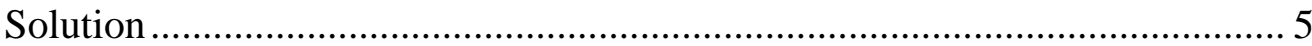

Table 3.2-2 Corrosion Test Protocol During ECC-HST for Testing Control Options Testing of the Deposition Tank...................................................................... 6

Table 3.3-1 Chemical Compositions (\%) for A537 Carbon Steel, Class 1, and Type 304L Stainless Steel ...................................................................................... 7

Table 3.3-2 Dimensions and Surface Areas of Corrosion Test Coupons........................... 8

Table 4.2-1 Electrochemical Measurements of A537 in Uninhibited Effluent - 2.5\% OA Sludge Dissolution .............................................................................. 13

Table 4.2-2 Effluent Chemistry Parameters Measured For Uninhibited Effluent - 2.5\% OA Sludge Dissolution ........................................................................... 14

Table 4.2-3 Pit Measurements in Uninhibited Effluent from Decomposition of 2.5\% OA Dissolved H-area and F-area Sludge ......................................................... 15

Table 4.3-1 Average Corrosion Rates of A537 and 304L Immersion Coupons in Uninhibited Effluents - 1\% OA Sludge Dissolution .................................... 17

Table 4.3-2 Electrochemical Measurements in Uninhibited Effluent - 1\% OA Sludge

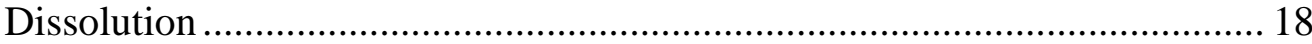

Table 4.3-3 Effluent Chemistry Parameters Measured For Uninhibited (No Light) Effluent - 1\% OA Sludge Dissolution....................................................................... 19

Table 4.4.1-1 Electrochemical Data for 1-F Series Coupons............................................ 21

Table 4.4.1-2 Effluent Chemistry Parameters Measured for F-area Based Effluent Mixed with Supernates ........................................................................................... 23

Table 4.4.2-1 Electrochemical Data for 1-H Series Coupons ............................................ 24

Table 4.4.2-2 Effluent Chemistry Parameters Measured for H-area Based Effluent Mixed

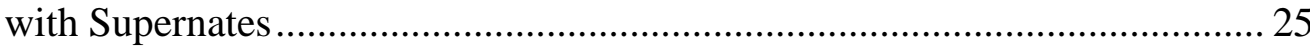

Table 4.4.3-1 Electrochemical Data for 2-F Series Coupons............................................. 27

Table 4.4.3-2 Effluent Chemistry Parameters Measured for F-area Based Effluent Mixed

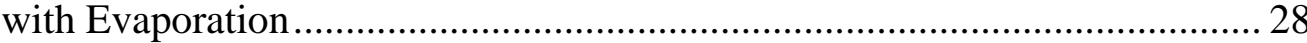

Table 4.4.4-1 Electrochemical Data for 2-H Series Coupons .......................................... 29

Table 4.4.4-2 Effluent Chemistry Parameters Measured for F-area Based Effluent Mixed with Evaporation....

Table 5-1 Summary of Average Corrosion Rates of A537 Carbon Steel in ECC-HST Test Solutions at $50{ }^{\circ} \mathrm{C}$ 
SRNL-STI-2011-00428, REVISION 0

\subsection{EXECUTIVE SUMMARY}

An Enhanced Chemical Cleaning (ECC) process is being developed to aid in the high level waste tank closure at the Savannah River Site. The ECC process uses an advanced oxidation process (AOP) to destroy the oxalic acid that is used to remove residual sludge from a waste tank prior to closure. The AOP process treats the dissolved sludge with ozone to decompose the oxalic acid through reactions with hydroxyl radicals. The effluent from this oxalic acid decomposition is to be sent to a Type III waste tank and may be corrosive to these tanks. As part of the hazardous simulant testing that was conducted at the ECC vendor location, corrosion testing was conducted to determine the general corrosion rate for the deposition tank and to assess the susceptibility to localized corrosion, especially pitting. Both of these factors impact the calculation of hydrogen gas generation and the structural integrity of the tanks, which are considered safety class functions.

The testing consisted of immersion and electrochemical testing of A537 carbon steel, the material of construction of Type III tanks, and 304L stainless steel, the material of construction for transfer piping. Tests were conducted in solutions removed from the destruction loop of the prototype ECC set up. Hazardous simulants, which were manufactured at SRNL, were used as representative sludges for F-area and H-area waste tanks. Oxalic acid concentrations of 1 and 2.5\% were used to dissolve the sludge as a feed to the ECC process. Test solutions included the uninhibited effluent, as well as the effluent treated for corrosion control. The corrosion control options included mixing with an inhibited supernate and the addition of hydroxide. Evaporation of the uninhibited effluent was also tested since it may have a positive impact on reducing corrosion. All corrosion testing was conducted at $50{ }^{\circ} \mathrm{C}$.

The uninhibited effluent was found to increase the corrosion rate by an order of magnitude from less than 1 mil per year (mpy) for an inhibited waste to a range of 5 to 23.4 mpy, depending on sludge chemistry. F-area-based effluents were, in general, more corrosive. Effective corrosion control measures included evaporation, hydroxide additions and mixing with supernates containing a representative supernate chemistry (5 M hydroxide and $1.5 \mathrm{M}$ nitrite). Corrosion rates with these measures were generally $0.2 \mathrm{mpy}$. The A537 carbon steel was found to be susceptible to pitting when the corrosion control measure involved mixing the ECC effluent with a supernate chemistry having minimal inhibitor concentrations $(0.5 \mathrm{M}$ hydroxide and $0.3 \mathrm{M}$ nitrite). Corrosion rates in this case were near $1 \mathrm{mpy}$. 


\subsection{INTRODUCTION}

An Enhanced Chemical Cleaning (ECC) process is being developed by Savannah River Remediation (SRR) to aid in Savannah River Site (SRS) High-Level Waste (HLW) tank closure. After bulk waste removal, the ECC process can be used to dissolve and remove much of the remaining sludge from HLW tanks. ECC is similar to the baseline chemical cleaning technology in that oxalic acid (OA) is used for sludge dissolution. The ECC process differs from the baseline technology in that a dilute OA (1-2.5\%) is used in place of concentrated OA (8\%) and that the resultant oxalate is decomposed using an Advanced Oxidation Process (AOP). Reducing the amount of OA used for dissolution and the subsequent oxidative destruction of $\mathrm{OA}$ will lead to a reduction of downstream impacts. Initial efficacy tests by AREVA, the ECC process vendor, demonstrated that tank heel simulants could be dissolved using dilute OA. The oxalate could be decomposed by an AOP that utilized ozone and ultraviolet (UV) light, and the resultant metal oxides and hydroxides could be separated out of the process [1].

As part of this development through a Task Technical Request (TTR), the Material Science \& Technology organization of the Savannah River National Laboratory (SRNL) directed corrosion testing at AREVA in Lynchburg, VA as part of the Hazardous Simulant Testing (HST) [2]. Specifically, the testing concerned corrosion of the deposition tank by effluents from the ECC destruction loop with a primary result being the determination of a deposition tank corrosion rate, which has a Safety Class functional classification [3]. This report provides the results of that testing, which were associated with subtasks S-HS-4 and S-HS-5 of the TTR and the Task Technical and Quality Assurance Plan [4].

\subsection{EXPERIMENTAL PLAN AND PROCEDURE}

The corrosion testing was conducted in two major phases during the ECC-HST. The first phase (AREVA Tasks 2 and 11) evaluated the corrosiveness of the solution exiting the destruction loop and is referred to as the uninhibited effluent. This solution provided a worse case condition of an uninhibited stream with the possible presence of hydroxyl radicals and secondary oxidizers that might impact corrosion if they had extended lifetimes. This testing was initiated with 1\% OA used for the dissolution of the sludge simulant. The destruction loop was operated under three conditions for the UV lamp; no lamp, a clean lamp, and a dirty lamp. After this testing was completed, the desired OA concentration for dissolution was changed from 1\% (Task 2) to 2.5\% (Task 11). The corrosion testing was repeated, but the destruction loop was operated without the UV lamp.

The second phase (AREVA Task 4) of testing evaluated the corrosion of the deposition tank with normal process options used for corrosion control or with evaporation which may have a positive impact on reducing corrosion. The destruction loop was operated without the UV lamp and the OA concentration was 2.5\%. The corrosion control options included the addition of inhibitor and the mixing of the uninhibited effluent with two supernate chemistries of the waste tanks. 
For both these phases of testing, F-area and H-area sludge simulants were used [15]. These simulant were tailored for the waste tanks in each area. The F-area and H-area sludges are frequently referred to as PUREX and HM sludges, respectively.

This section discusses the corrosion test techniques, test protocol, the test samples and solutions, and post-test analysis of the samples and the data. The details of the corrosion test results and analysis are found in laboratory notebook, SRNL-NB-2009-00152. Corrosion testing was conducted by AREVA personnel and data analysis by SRNL. The AREVA test details are found in test report and data packages supplied to SRR [18-24].

\subsection{CORROSION TEST TECHNIQUES, PROCEDURES AND EQUIPMENT}

The corrosion testing consisted of electrochemical and immersion coupon tests performed simultaneously in the same solution. These tests are used to assess both the general corrosion rate of the carbon steel and the susceptibility of the carbon steel to localized corrosion. An SRNL R\&D direction was used to specify the necessary parameters for performing the corrosion tests, which were incorporated into an AREVA procedure for conducting the test $[5,6]$. AREVA personnel were trained on the corrosion test procedure and operation of the electrochemical test equipment prior to the start of testing [7].

For the electrochemical testing, three different electrochemical techniques were performed. First, open-circuit potential monitoring (OCP) was performed as the sample stabilized over the first hour of exposure in the test solution. Immediately following, a linear polarization resistance (LPR) test was conducted. This test measured the responding current over a small range of polarized potentials $(40 \mathrm{mV})$ around the open-circuit potential. From these current and potential measurements an instantaneous general corrosion rate was determined. The test were conducted with a scan rate of $0.25 \mathrm{mV} / \mathrm{sec}$. LPR was performed every hour during the time of exposure, which varied depending on the phase of testing.

The third technique, which is used to assess localized corrosion, was cyclic potentiodynamic polarization (CPP). For most test conditions, this test was performed once at the conclusion of exposure. The potential was scanned over a much larger range than LPR, from $100 \mathrm{mV}$ electronegative of the initial open-circuit potential to a vertex potential, approximately $1 \mathrm{~V}$ electropositive of the open-circuit potential, and scanned back to the open-circuit potential. The scan rate was $0.25 \mathrm{mV} / \mathrm{sec}$.

The immersion coupon testing consisted of exposing pre-weighed coupons to the same solution as used for the electrochemical test. The immersion coupons were exposed for the entire series of electrochemical tests and the exposure time was recorded. After post-test cleaning, coupons were weighed and the weight loss and exposure time were used to calculate a time-averaged corrosion rate. SRNL weighed the coupons both before and after exposure on balances controlled as M\&TE.

The corrosion tests were conducted in borosilicate glass cells designed to accommodate both the immersion and electrochemical coupons, which are described in greater detail in Section 3.3. For the electrochemical testing, the other required electrodes included a 0.25 -inch diameter graphite rod (counter electrode) and a Ag/AgCl reference electrode. The test 
vessels were sized so that the ratio of the solution volume to the total coupon surface area was $125 \pm 5 \mathrm{ml}$ to $1 \mathrm{in}^{2}$ [27]. Figure 3.1-1 shows the test cell for the first phase, as described in Section 3.0, of testing with the cell components identified. The cell for the second phase of testing was similar except using a smaller volume since fewer coupons were immersed in the solution (See Section 3.3 Test Samples). The test cells were placed into a water bath and maintained at $50{ }^{\circ} \mathrm{C} \pm 5{ }^{\circ} \mathrm{C}$. The temperature was monitored by an independent thermocouple. This temperature provided a conservative condition with thermal acceleration of the corrosion process without depleting the solution oxygen concentration.

The electrochemical test equipment used for this testing was a potentiostat, a multiplexer, and a laptop computer. Two independent test set ups were provided to accommodate the number of specified tests [4]. SRNL supplied a Gamry ${ }^{\mathrm{TM}}$ PCI4-750 and a Gamry ${ }^{\mathrm{TM}} 600$ Potentiostat, two Gamry ${ }^{\mathrm{TM}}$ ECM8 Multiplexers, and two laptop computers which contained DC105 DC Corrosion Testing Software ${ }^{\mathrm{TM}}$ for controlling the test. The equipment was provided to AREVA through a DOE-approved loan agreement [8]. All the equipment was returned to site upon completion of the testing.

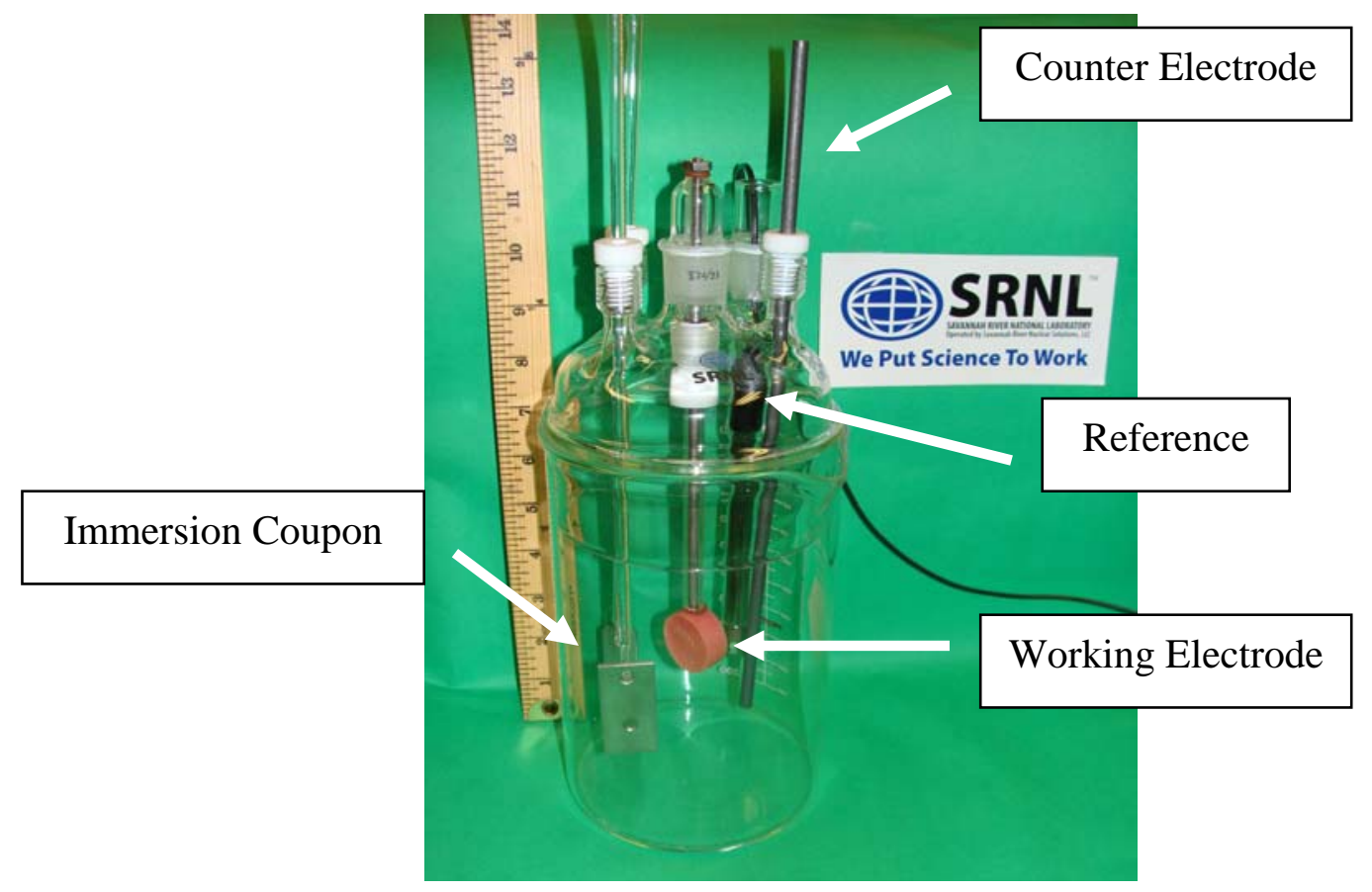

Figure 3.1-1 Corrosion test cell for testing in uninhibited effluent from the destruction loop.

\subsection{TEST PROTOCOLS}

The protocol for the corrosion testing at AREVA differed for the two phases. In the first phase with uninhibited effluent (AREVA Tasks 2 and 11), the test coupons were exposed to three batches of solution siphoned from the exit stream of the destruction loop which was operated at one of three different UV lamp conditions (clean UV, dirty UV, no UV). A batch was taken from the destruction loop each time a fresh batch of oxalic acid was added to the sludge simulant for dissolution then processed through the loop. Testing was performed with both F-area and H-area sludge simulants [15]. The coupons were exposed to each batch for 
approximately eighteen hours. During the first two batches, the OCP and LPR were performed. On the third batch, OCP, LPR and CPP were performed. The same coupons were used for all three batches, except when the electrochemical coupon malfunctioned during testing. Table 3.2-1 lists the test conditions along with the AREVA test designation for testing in the uninhibited effluent.

Table 3.2-1 Corrosion Test Protocol during ECC-HST with Uninhibited Effluent

\begin{tabular}{|c|c|c|c|c|c|}
\hline $\begin{array}{c}\text { AREVA } \\
\text { Test } \\
\text { Number }\end{array}$ & $\begin{array}{c}\text { OA } \\
\text { Conc. } \\
(\%)\end{array}$ & $\begin{array}{l}\text { UV Lamp } \\
\text { Condition }\end{array}$ & $\begin{array}{l}\text { Sludge } \\
\text { Type }\end{array}$ & $\begin{array}{l}\text { Batch } \\
\text { Number }\end{array}$ & $\begin{array}{c}\text { Electrochemical } \\
\text { Test }\end{array}$ \\
\hline \multirow{2}{*}{$\mathrm{H}-\mathrm{NL}$} & \multirow{2}{*}{1} & \multirow{2}{*}{ None } & \multirow{2}{*}{ H-area } & 1,2 & OCP, LPR \\
\hline & & & & 3 & OCP, LPR, CPP \\
\hline \multirow{2}{*}{$\mathrm{H}-\mathrm{CL}$} & \multirow{2}{*}{1} & \multirow{2}{*}{ Cleaned } & \multirow{2}{*}{ H-area } & 1,2 & OCP, LPR \\
\hline & & & & 3 & OCP, LPR, CPP \\
\hline \multirow{2}{*}{$\mathrm{H}-\mathrm{DL}$} & \multirow{2}{*}{1} & \multirow{2}{*}{ Dirty } & \multirow{2}{*}{ H-area } & 1,2 & OCP, LPR \\
\hline & & & & 3 & OCP, LPR, CPP \\
\hline \multirow{2}{*}{ F-NL } & \multirow{2}{*}{1} & \multirow{2}{*}{ None } & \multirow{2}{*}{ F-area } & 1,2 & OCP, LPR \\
\hline & & & & 3 & OCP, LPR, CPP \\
\hline \multirow{2}{*}{ F-CL } & \multirow{2}{*}{1} & \multirow{2}{*}{ Cleaned } & \multirow{2}{*}{ F-area } & 1,2 & OCP, LPR \\
\hline & & & & 3 & OCP, LPR, CPP \\
\hline \multirow{2}{*}{ F-DL } & \multirow{2}{*}{1} & \multirow{2}{*}{ Dirty } & \multirow{2}{*}{ F-area } & 1,2 & OCP, LPR \\
\hline & & & & 3 & OCP, LPR, CPP \\
\hline \multirow{2}{*}{ A-H-NL- } & \multirow{2}{*}{2.5} & \multirow{2}{*}{ None } & \multirow{2}{*}{ H-area } & 1,2 & OCP, LPR \\
\hline & & & & 3 & OCP, LPR, CPP \\
\hline \multirow{2}{*}{ A-F-NL } & \multirow{2}{*}{2.5} & \multirow{2}{*}{ None } & \multirow{2}{*}{ F-area } & 1,2 & OCP, LPR \\
\hline & & & & 3 & OCP, LPR, CPP \\
\hline
\end{tabular}

In the second phase of testing (AREVA Task 4), corrosion testing was performed in the uninhibited effluent from the destruction loop that was modified either to simulate tank farm process options for minimizing corrosion of the waste tanks or with evaporation which has been noted to have a positive impact in reducing corrosion. The three tested options were 1) evaporation, 2) adjustment with hydroxide to $1.2 \mathrm{M}$ free hydroxide, and 3) mixing with the supernate heel in the tank. Two supernate heel chemistries were used. Table 3.2-2 shows the list of ten process conditions downstream from the destruction loop that were tested. These conditions included planned and upset conditions that could result in either the evaporator, hydroxide addition or both being unavailable. The shading in the table shows tests that were performed with the uninhibited effluent from the same batch. These corrosion tests were also conducted simultaneously.

The two supernate chemistries that were used in this testing represented an upper bound nitrate concentration and a representative nitrate concentration. The typical nitrate concentration range for the Type III tanks is between 1 and $2 \mathrm{M}$. For the upper bound condition, the supernate chemistry was $2.0 \mathrm{M}$ nitrate, $0.3 \mathrm{M}$ nitrite and $0.5 \mathrm{M}$ hydroxide, which are within the corrosion control program limits. The representative chemistry was 1.6 
$\mathrm{M}$ nitrate, 1.5 $\mathrm{M}$ nitrite, and $5 \mathrm{M}$ hydroxide. The upper bound nitrate tests are $1 \mathrm{a}$ and $2 \mathrm{a}$ and the representative nitrate tests are $1 \mathrm{~b}$ and $2 \mathrm{~b}$ in Table 3.2-2. For cases $3-8$, the effluent was blended with the supernate containing the upper bound nitrate concentration and treated with a combination of evaporation and hydroxide adjustment. The ratio of the uninhibited effluent to supernate heel was 2:5, which is based on a worse case volume ratio for the ECC daily process output to a tank heel.

Table 3.2-2 Corrosion Test Protocol during ECC-HST for Testing Corrosion Control Options of the Deposition Tank

\begin{tabular}{|c|c|c|c|c|}
\hline $\begin{array}{l}\text { Test Case } \\
\text { (Areva } \\
\text { Number) }\end{array}$ & Evaporator* & $\begin{array}{c}\text { Hydroxide } \\
\text { Adjustment* }\end{array}$ & $\begin{array}{c}\text { Sludge } \\
\text { Simulant } \\
\text { Utilized }\end{array}$ & Supernate Condition \\
\hline $\begin{array}{c}1 \mathrm{a} \\
(1-\mathrm{F})\end{array}$ & $\mathrm{N}$ & $\mathrm{N}$ & F-area & $\begin{array}{l}\text { Supernate heel at minimum } \\
\text { inhibitor levels }\end{array}$ \\
\hline $\begin{array}{c}1 \mathrm{~b} \\
(1-\mathrm{F})\end{array}$ & $\mathrm{N}$ & $\mathrm{N}$ & F-area & $\begin{array}{l}\text { Supernate heel at } \\
\text { representative supernate } \\
\text { concentration }\end{array}$ \\
\hline $\begin{array}{c}2 \mathrm{a} \\
(1-\mathrm{H})\end{array}$ & $\mathrm{N}$ & $\mathrm{N}$ & H-area & $\begin{array}{l}\text { Supernate heel at minimum } \\
\text { inhibitor levels }\end{array}$ \\
\hline $\begin{array}{c}2 \mathrm{~b} \\
(1-\mathrm{H})\end{array}$ & $\mathrm{N}$ & $\mathrm{N}$ & H-area & $\begin{array}{l}\text { Supernate heel at } \\
\text { representative supernate } \\
\text { concentration }\end{array}$ \\
\hline $\begin{array}{c}3 \\
(1-F)\end{array}$ & $\mathrm{N}$ & $\mathrm{Y}$ & F-area & $\begin{array}{l}\text { Supernate heel at minimum } \\
\text { inhibitor levels }\end{array}$ \\
\hline $\begin{array}{c}4 \\
(1-\mathrm{H})\end{array}$ & $\mathrm{N}$ & Y & H-area & $\begin{array}{l}\text { Supernate heel at minimum } \\
\text { inhibitor levels }\end{array}$ \\
\hline $\begin{array}{c}5 \\
(2-F)\end{array}$ & $\mathrm{Y}$ & $\mathrm{N}$ & F-area & $\begin{array}{c}\text { Supernate heel at minimum } \\
\text { inhibitor levels }\end{array}$ \\
\hline $\begin{array}{c}6 \\
(2-\mathrm{H})\end{array}$ & $\mathrm{Y}$ & $\mathrm{N}$ & H-area & $\begin{array}{c}\text { Supernate heel at minimum } \\
\text { inhibitor levels }\end{array}$ \\
\hline $\begin{array}{c}7 \\
(2-F)\end{array}$ & $\mathrm{Y}$ & $\mathrm{Y}$ & F-area & $\begin{array}{c}\text { Supernate heel at minimum } \\
\text { inhibitor levels }\end{array}$ \\
\hline $\begin{array}{c}8 \\
(2-H)\end{array}$ & $\mathrm{Y}$ & $\mathrm{Y}$ & H-area & $\begin{array}{l}\text { Supernate heel at minimum } \\
\text { inhibitor levels }\end{array}$ \\
\hline
\end{tabular}

* $\mathrm{Y}$ - condition used during testing, $\mathrm{N}$ - condition not used during testing

Additional data, the oxidation-reduction potential (ORP), solution $\mathrm{pH}$, and solution chemistries, were obtained to evaluate the corrosion of carbon steel in the deposition tank environment. These three factors can have significant effects on the corrosion rate. The ORP provides a measure of the oxidizing power of the solutions, while $\mathrm{pH}$ can alter the passivity and the corrosion resistance of the materials of construction.

\subsection{TEST SAMPLES}

The test samples were made of either A537, Class 1 carbon steel (A537), which is the material of construction for the deposition tanks (Type III waste tanks) or Type 304L stainless steel (304L), a possible material of construction for the ECC transfer piping. Nominal compositions for these materials are given in Table 3.3-1. 
Table 3.3-1 Chemical Compositions (\%) for A537 Carbon Steel, Class 1, and Type 304L Stainless Steel

\begin{tabular}{|c|c|c|c|c|c|c|c|c|}
\hline Material & Fe & C & Mn & Cr & Ni & P & S & Other \\
\hline A537 & Bal & 0.18 & 1.31 & 0.16 & 0.18 & 0.018 & 0.01 & $\begin{array}{c}\text { Cu-0.157 } \\
\text { Mo-0.055 }\end{array}$ \\
\hline 304L* & Bal & 0.03 & 2.0 & $18-20$. & $8-10$ & 0.045 & 0.03 & 0.75 \\
\hline
\end{tabular}

* Maximum concentration

For the first phase of testing in the uninhibited effluent, the vessels each contained one A537 electrochemical coupon, one A537 immersion coupon, and one 304L immersion coupon. One set of coupons was used for the three batches of each test condition. As shown in Figure $3.3-1$, the electrochemical coupons were approximately 0.5 ” x 0.5 ” in size and placed in a 1 ” diameter metallurgical mount. The material used for the electrochemical coupons was from the same lot of material used to make the immersion coupons. Prior to mounting, a wire was attached to the back of the coupon and was used for connection to the electrochemical equipment.

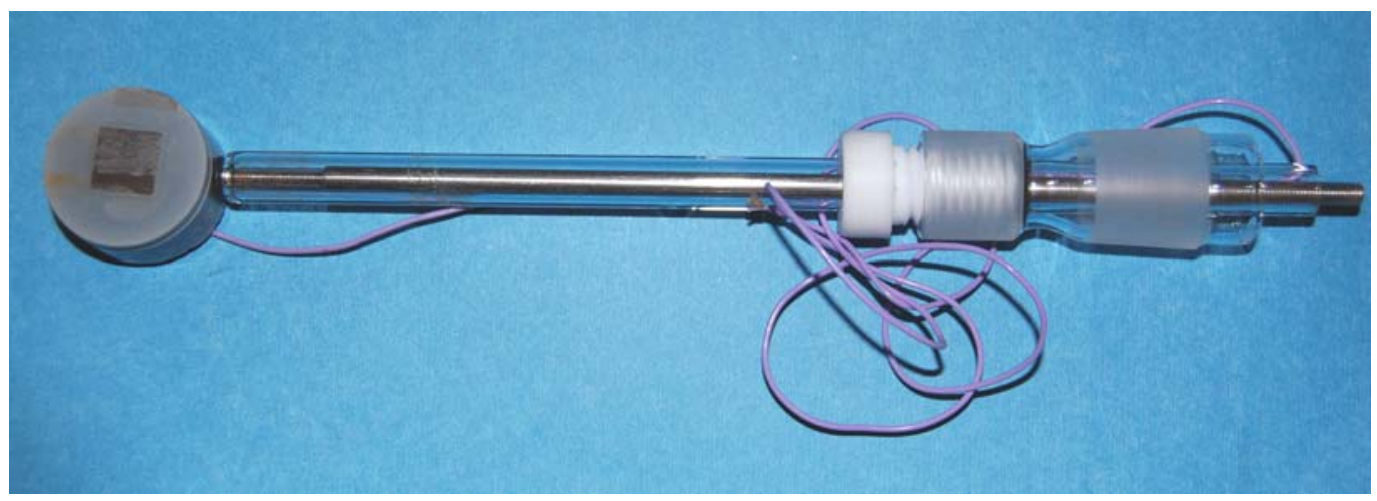

Figure 3.3-1 Mounted electrochemical coupon in sample holder for ECC-HST.

The coupon dimensions and surface areas are given in Table 3.3-2. These surface areas were used to calculate the total solution volume based on the required $125 \mathrm{ml}( \pm 5 \mathrm{ml})$ of solution per in ${ }^{2}$ of coupon surface area.

For the second phase of testing, the vessels each contained two A537 coupons, one electrochemical and one immersion. The dimensions and surface area of the coupons are given in Table 3.3-2. These surface areas were used to calculate the total solution volume based on the required $125 \mathrm{ml}( \pm 5 \mathrm{ml})$ of solution per in $^{2}$ of coupon surface area.

The A537 immersion coupons had a different surface finish on each side. The front side, which had the coupon identification number and material type imprinted, had a coarse surface from a 320-grit finishing paper. The back side had a 600-grit surface finish and a smooth appearance. The 304L coupons had a 600-grit finish on both sides. 
Table 3.3-2 Dimensions and Surface Areas of Corrosion Test Coupons

\begin{tabular}{|c|c|c|c|}
\hline Coupon Type & Material & Dimensions* (in.) & Surface Area** (in $\left.^{\mathbf{2}}\right)$ \\
\hline Immersion & A537 & $1 \times 2 \times 0.14-0.375$ & 4.8 \\
\hline & 304L & $1 \times 2 \times 0.25-0.2$ & 5.6 \\
\hline Electrochemical $^{* * *}$ & A537 & $0.5 \times 0.5$ & 0.25 \\
& & $0.5 \times 0.4$ & 0.2 \\
\hline
\end{tabular}

* Immersion: width $\times$ length $\times$ thickness - support hole diameter Electrochemical: width $\times$ length

** Immersion $\mathrm{SA}=2(\mathrm{w} * \mathrm{l})+2\left(\mathrm{w}^{*} \mathrm{t}\right)+2(1 * \mathrm{t})-2\left(\pi \mathrm{r}^{2}\right)+2(\pi \mathrm{rt})$, where $\mathrm{r}$ is hole radius Electrochemical SA $=\mathrm{w} \times \mathrm{l}$.

*** The electrochemical coupons with a surface area of $0.2 \mathrm{in}^{2}$ were used only for the first phase of testing in $2.5 \%$

SRNL personnel weighed the immersion coupons using an M\&TE balance both before and after the exposure to use in calculating the general corrosion rate. The weight of each coupon was measured non-sequentially twice. ASTM G1 standard was used to guide the cleaning and weighing procedures [9]. At the conclusion of a test, the coupons were thoroughly rinsed and dried by AREVA personnel and packaged with a desiccant to prevent further corrosion prior to shipment to SRNL for analysis.

\subsection{DATA ANALYSIS}

The corrosion rates calculated for both the immersion and the electrochemical coupons are based on standard methodology as specified in ASTM practices and standards [9-11]. The immersion coupon corrosion rates were calculated from weight loss measurements on the coupons. The weight loss corrosion rate $\left(\mathrm{CR}_{\mathrm{wl}}\right)$ was obtained by the following equation:

$$
\mathrm{CR}_{\mathrm{wl}}=(\mathrm{K} \times \mathrm{W}) /(\mathrm{A} \times \mathrm{T} \times \mathrm{D})
$$

where: $\mathrm{K}-\mathrm{a}$ conversion constant $\left(3.45 \times 10^{6}\right.$ for units in mils per year (mpy))

$\mathrm{W}$ - coupon weight loss, calculated from pre- and post-exposure weights (grams)

A - coupon surface area $\left(\mathrm{cm}^{2}\right)$

$\mathrm{T}$ - exposure time (hours)

$\mathrm{D}$ - material density $\left(7.86 \mathrm{~g} / \mathrm{cm}^{3}\right.$ for A537 and $7.94 \mathrm{~g} / \mathrm{cm}^{3}$ for 304L)

The electrochemical corrosion rate was calculated from the data obtained during the LPR. From the measured current and potential data, a polarization resistance (RP) value is obtained, which is related to the corrosion current ( $\left.\mathrm{i}_{\text {corr }}\right)$ by the following equation:

$$
\mathrm{i}_{\text {corr }}=10^{6} \times(\mathrm{B} / \mathrm{RP})
$$

where B is a constant based on the anodic and cathodic Tafel slopes, taken as $120 \mathrm{~V} /$ decade for these materials in an oxygenated environment. The instantaneous corrosion rate $\left(\mathrm{CR}_{\mathrm{i}}\right)$ is calculated from $\mathrm{i}_{\text {corr }}$ by the following equation:

$$
\mathrm{CR}_{\mathrm{i}}=0.1288\left(\mathrm{i}_{\text {corr }} \times \mathrm{EW}\right) / \mathrm{D}
$$


where: EW - equivalent weight, which for A537 is 27.9

$\mathrm{D}$ - material density $\left(7.86 \mathrm{~g} / \mathrm{cm}^{3}\right.$ for A537)

\subsection{TECHNICAL DATA QUALITY TO SUPPORT SAFETY CLASS FUNCTIONAL CLASSIFICATION}

The corrosion data gathered from the electrochemical and coupon immersion tests using both 1 and 2.5 wt\% OA will be utilized to assess the degradation of the waste tank. The corrosion rates calculated from the coupon immersion weight losses will be utilized to estimate the degradation to safety class equipment (i.e., waste tank), so must meet certain qualifications. The following activities were taken to ensure the quality of the data for corrosion rate calculations for all phases of testing.

1) Obtained the mill certificate for the A537 carbon steel utilized for the tests.

2) Ensured that the balances utilized to determine the weight of the coupons were M\&TE.

3) Testing was conducted using an SRNL R\&D direction.

The original TTR and TTQAP associated with this task, which initially covered only 1 wt\% OA used during the ECC-HST, had no requirements to support safety class operations After start of the testing, SRR revised the TTR to include the use of $2.5 \mathrm{wt} \%$ OA during the ECCHST and to require that the data support safety class operations. The procedural controls and requirements, as given above, that were utilized for acquisition of safety class data during the the $2.5 \mathrm{wt} \%$ OA ECC-HST were identical to those that had been established for the $1 \mathrm{wt} \%$ OA data acquisition. Per the E7 manual, procedure 3.7, equivalent controls were used to gather the weight loss data used in the corrosion rate calculations [25], so both sets of data are qualified.

The corrosion rate calculations are also directly dependent on the measured time exposure and indirectly dependent on the test temperature and initial oxalic acid concentration, which impacts the overall weight loss. The data acquisition for these parameters has been qualified by SRR [29].

Additionally, to ensure the data quality of the electrochemical data, the potentiostats were tested according to ASTM G5 standard [12]. ASTM G5 provides an experimental procedure for checking experimental technique and equipment. If the procedure is followed correctly, the generated data should reproduce standard data established from round robin testing, which is given in the standard.

As specified in ASTM G5, a 430 stainless steel coupon was exposed to a $1 \mathrm{~N}$ sulfuric acid solution that had been deaerated. Argon gas was bubbled through the solution for at least 30 minutes prior to immersing the coupon and continuously during the test. The OCP of the sample was measured for 60 minutes prior to performing the potentiodynamic polarization. A Ag/AgCl reference electrode was used to measure the potential. Complete details for performing this test can be found in the standard [12] and the test results are given in Section 4.1 ASTM G5 Standard Test Results. 


\subsection{RESULTS}

The electrochemical and immersion corrosion test results from the AREVA ECC-HST testing are divided into two sections: results from testing in the uninhibited effluent from the destruction loop with either 1 or $2.5 \%$ OA used for sludge dissolution (AREVA Tasks 2 and 11 ) and results from testing in 2.5\% OA-based effluents treated for corrosion control or with evaporation (AREVA Task 4). Data from the ASTM G5 reference tests are also presented.

\subsection{ASTM G5 STANDARD TEST RESULTS}

The ASTM G5 standard was performed both before and after the electrochemical equipment was used at AREVA for the $2.5 \%$ oxalic acid testing. The potentiodynamic scans for each potentiostat are shown in Figure 4.1-1. The potentials are shown measured versus a saturated calomel electrode (SCE), which was used in the standard for data presentation. The SCE and $\mathrm{Ag} / \mathrm{AgCl}$ reference, which was used for conducting this testing, differ by $0.0445 \mathrm{~V}$. The black bars in the figure indicate the range of current density values at specific potentials as given in the ASTM G5 standard from round-robin testing. As can be seen in the figure, the current values for the potentiostats were at or near the limits of the round-robin testing. The data indicates that the equipment was operating correctly and generating reproducible data.

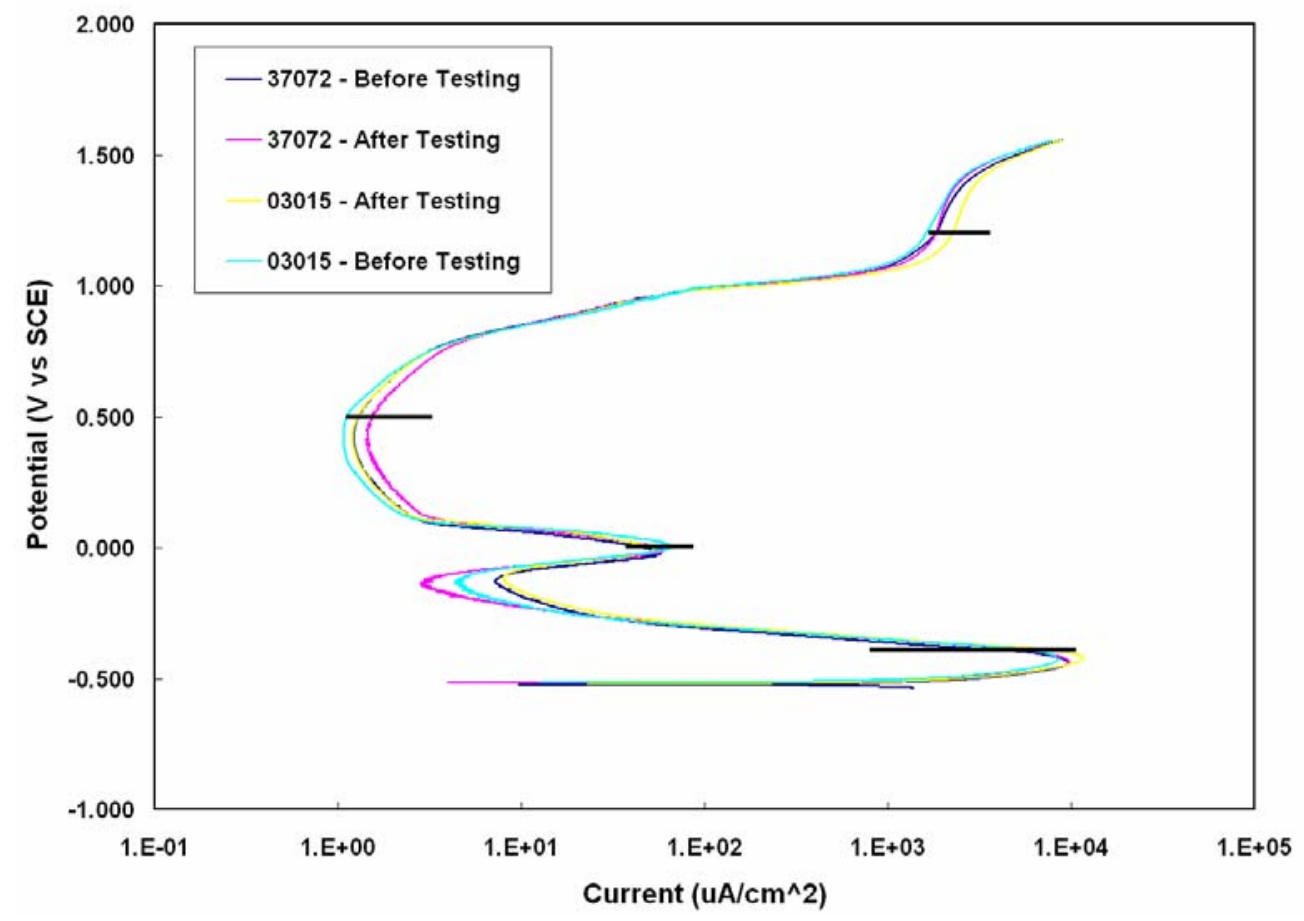

Figure 4.1-1 Potentiodynamic scans performed according to ASTM G5 for potentiostats used during ECC-HST corrosion testing. 


\subsection{UNINHIBITED EFFLUENT - 2.5\% OXALIC ACID}

These tests were performed without the UV lamp operating during the OA decomposition in the destruction loop. The coupons were exposed for 65 hours to uninhibited effluent from decomposition of OA-dissolved F-area sludge and 74 hours to uninhibited effluent from decomposition of OA-dissolved H-area sludge. Both the A537 electrochemical and immersion coupons had corrosion products that covered most of the surface and ranged in coloring from black/blue to rust. Figure 4.2-1 (A) shows an immersion coupon that was exposed to the uninhibited effluent from an F-area sludge OA dissolution. The 304L immersion coupons were also covered with a rust-color corrosion product or rust staining as shown in Figure 4.2-1 (B).

After cleaning, the samples were found to have varying degrees of corrosion damage. All the A537 coupons were pitted and had areas of heavy general corrosion where the initial grinding marks were not observable. Within the areas of heavy general corrosion, pits could still be observed although they did not seem as prevalent as in areas of lesser general corrosion. Nominal pit dimensions were 2 to 2.5 mil diameters and 0.1 to 0.7 mil depths.

The pits appeared to fall along a line as shown in Figure 4.2-2. The pitting on these coupons is attributed to impurities aligned during the rolling of the initial plate material from which the coupons were fabricated. (The importance to the waste tank is discussed in Section 5.0) The A537CL1-51 coupon was sectioned and mounted for metallographic analysis. The microstructure of the sample is shown in Figure 4.2-3. The darker black phase is the ferrite while the lighter phase is the cementite. Note the small black impurities that fall along linear arrays.

The 304L immersion coupons had shiny metallic surfaces after cleaning, but small areas of attack were observed at higher-magnification examinations.

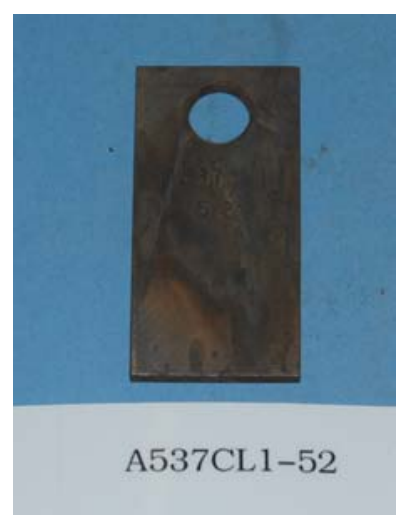

(A)

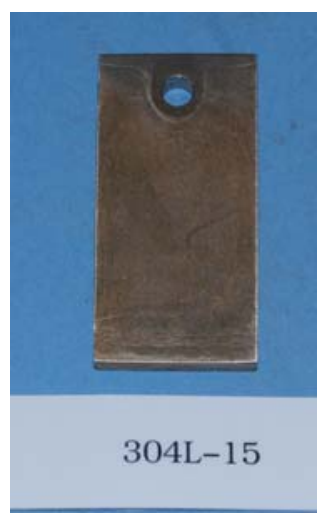

(B)

Figure 4.2-1 A537 (A) and 304L (B) immersion coupons after exposure in uninhibited effluent from decomposition of 2.5\% OA dissolved F-area sludge. 
SRNL-STI-2011-00428, REVISION 0

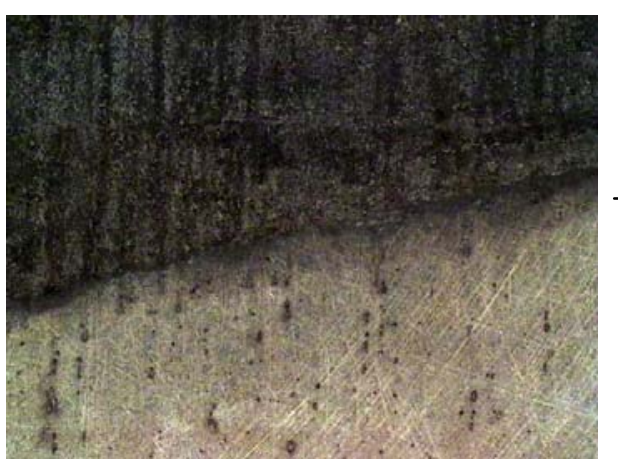

General and Pitting Corrosion

Pitting Corrosion

Figure 4.2-2 Stereomicroscope photograph (20x) of coupon A537CL1-51 after exposure in uninhibited effluent from decomposition of 2.5\% OA dissolved F-area sludge.

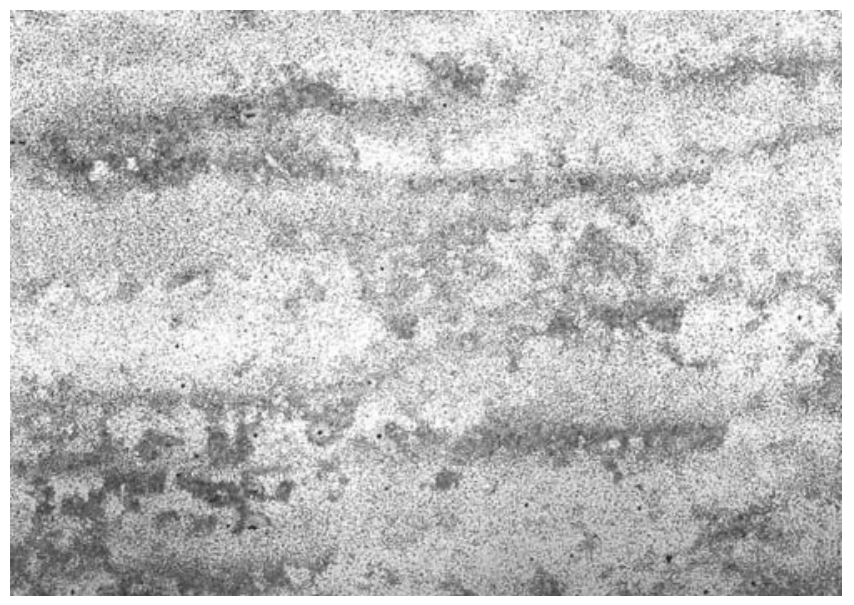

Figure 4.2-3 Metallograph of microstructure associated with coupon A537CL1-51.

The weight changes and corrosion rates for each immersion coupon are given in Appendix 1. The A537 immersion coupons had average corrosion rates of 8.4 and 13.6 mpy for the $\mathrm{H}$ and F-area sludge based effluents, respectively. The 304L immersion coupons had average corrosion rates of 1.7 and $1.9 \mathrm{mpy}$ for the $\mathrm{H}$ - and F-area sludge based effluents, respectively. For both the A537 and 304L immersion coupons, the difference in corrosion rates between the duplicate samples was greater in the uninhibited effluent associated with F-area sludge than the $\mathrm{H}$-area sludge, which may be associated with variation in sludge chemistry. Corrosion rates less than 2 mpy are considered excellent while rates from 2 to 20 mpy are considered good [26].

The electrochemical instantaneous corrosion rates were smaller than those measured by weight loss. Appendix II gives the instantaneous corrosion rates for each electrochemical coupon at the start and end of each batch. Table 4.2-1 shows the average instantaneous corrosion rates along with the OCP for the two coupons exposed to the H- and F-area based effluents. For the H-area sludge testing, the CPP scan was performed at the end of the first batch, so the LPR data for Batches 2 and 3 are not comparable to those for the F-area sludge since the surface was altered by performing the CPP scan. The data presented in Table 4.2-1 shows that the corrosion rate decreased with exposure time during one batch as well as all 
three batches (compare the F-area $1^{\text {st }}$ and $3^{\text {rd }}$ batch data). The OCP became less electronegative or more ennobled during exposure indicative of a growing oxide or a layer of corrosion products on the surface as observed in Figure 4.2-1. Similar to the immersion coupons, the instantaneous corrosion rates in the F-area sludge based effluents were greater than those in the H-area sludge based effluents.

Table 4.2-1 Electrochemical Measurements of A537 in Uninhibited Effluent - 2.5\% OA Sludge Dissolution

\begin{tabular}{|c|c|c|c|c|}
\hline \multirow{2}{*}{ Sludge Type } & \multicolumn{2}{|c|}{ Initial } & \multicolumn{2}{c|}{ Final } \\
\cline { 2 - 5 } & OCP (V) & Corrosion Rate (mpy) & OCP (V) & Corrosion Rate (mpy) \\
\hline F-area $-1^{\text {st }}$ batch & -672 & 11.5 & -650 & 4.9 \\
\hline F-area $-3^{\text {rd }}$ batch & -483 & 8.4 & -449 & 4.4 \\
\hline H-area $-1^{\text {st }}$ batch & -672 & 9.5 & -638 & 3.4 \\
\hline
\end{tabular}

The corrosion morphology of the electrochemical samples after testing was similar to those observed on the immersion coupons. Figure 4.2-4 shows a stereomicroscope photograph at 10x of electrochemical coupons exposed to the uninhibited effluent from the decomposition of OA dissolved F-area (A) and H-area (B) sludge. Pitting was seen uniformly across the surface with some area of high general corrosion (darker regions in photographs), although the pits were not in linear arrays. The high general corrosion was marked by a severelyattacked, variable-depth surface with no initial grinding marks apparent.

The CPP scans showed anodic dissolution with some indication of pitting. Figure 4.2-5 shows the CPP scans for coupons EC-A537-39 and EC-A537-41, which are pictured after testing in Figure 4.2-4. EC-A537-39, which was exposed to the F-area based effluent, has a slight positive hysteresis with a pit protection potential of $-0.396 \mathrm{~V}$. EC-A537-41 had a slight negative hysteresis. A positive hysteresis is indicative of pitting susceptibility and occurs when the current during the reverse scan is greater than the current during the forward scan. The OCP for EC-A537-41 was slightly more electronegative than the OCP for ECA537-39 since it was exposed to the effluent for the last batch only, while coupon EC-A53739 was exposed to the effluent for all three batches.

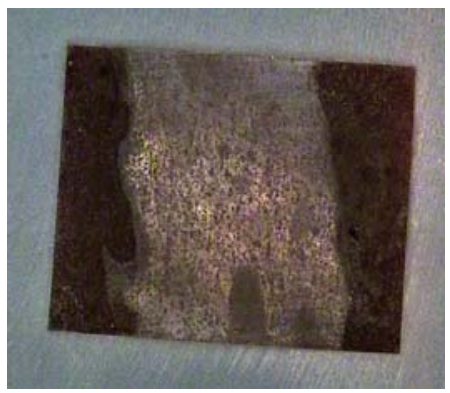

(A)

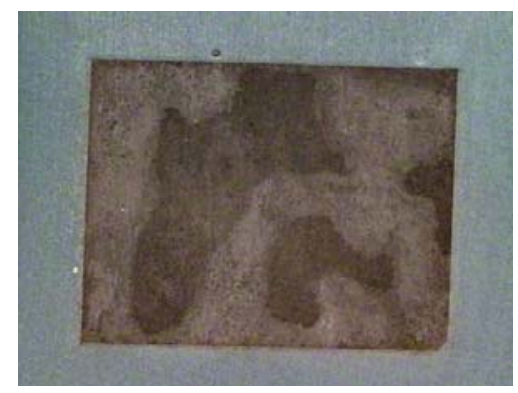

(B)

Figure 4.2-4 Stereomicroscope photograph (10x) of coupons EC-A537-39 (A) and ECA537-41 (B) after electrochemical testing in uninhibited effluent from decomposition of $2.5 \%$ OA dissolved F-area and H-area sludge, respectively. 


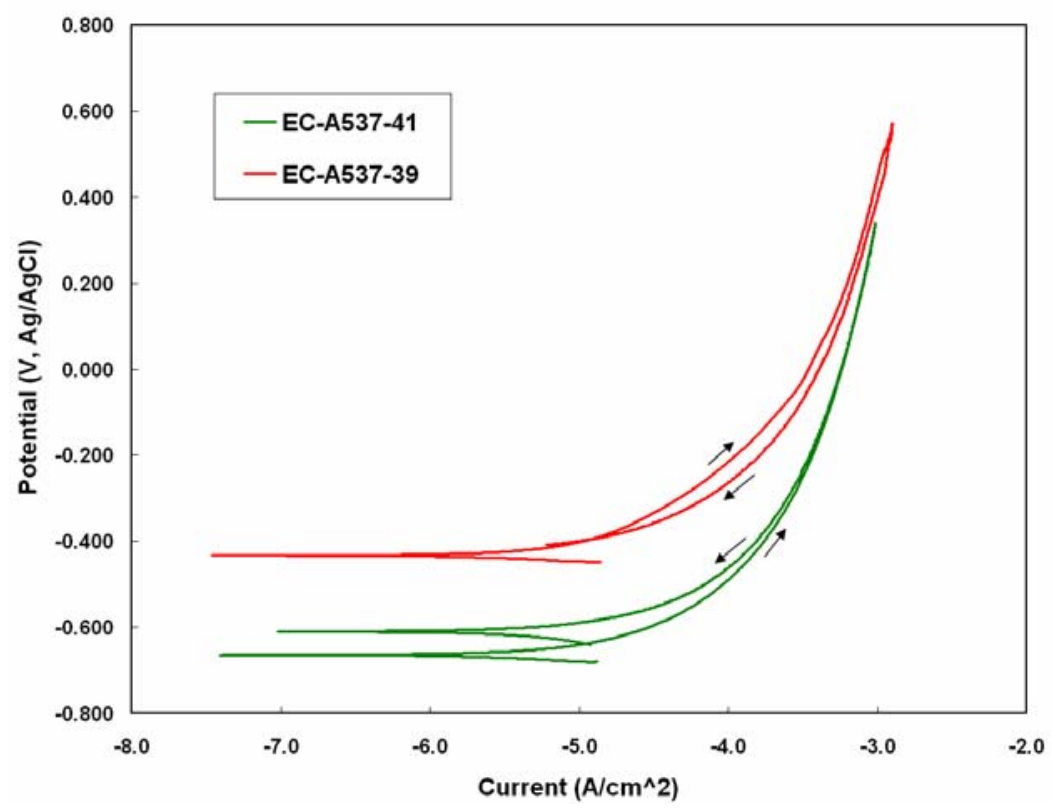

Figure 4.2-5 CPP scans for coupons EC-A537-39 and EC-A537-41 in effluent from decomposition of $2.5 \%$ OA dissolved F-area and $\mathrm{H}$-area sludge, respectively. Arrows indicate direction of scan.

The CPP scans for the H-area based effluent from both the first and third batch were identical displaying anodic dissolution with a slight negative hysteresis on the reverse scan. The OCP values were similar falling in the range of -640 to $-670 \mathrm{~V}$.

The effluent chemistry was characterized by the $\mathrm{pH}$, ORP, residual OA concentration and specific metal concentrations of $\mathrm{Al}, \mathrm{Fe}, \mathrm{Mn}, \mathrm{Ni}$, and $\mathrm{Hg}$. The ORP was measured during the test, while the remaining parameters were measured at the conclusion of testing. The $\mathrm{pH}$ and ORP of the uninhibited effluent for the two sludge chemistries were similar as shown by the data in Table 4.2-2. Only the Hg concentration is shown since the other metals would not impact the corrosion. Higher Hg concentration was noted in the F-area based effluent, while OA concentration was higher in the H-area based effluent.

Table 4.2-2 Effluent Chemistry Parameters Measured For Uninhibited Effluent - 2.5\% OA Sludge Dissolution

\begin{tabular}{|c|c|c|c|c|c|}
\hline Sludge & Batch & $\mathbf{p H}$ & ORP (V) & OA (ppm) & Hg (ppm) \\
\hline F-area & 1 & 8.5 & 235 & 90 & 1.56 \\
\hline & 2 & 8.2 & 272 & 45 & 2.3 \\
\hline & 3 & 8.0 & 505 & 23 & 0.24 \\
\hline H-area & 1 & 8.4 & 205 & 18 & 0.0 \\
\hline & 2 & 7.9 & 285 & 99 & 0.11 \\
\hline & 3 & 6.9 & 414 & 77 & 0.24 \\
\hline
\end{tabular}




\subsubsection{Scoping Study of Pitting Corrosion}

A scoping study of pitting corrosion in the destruction loop effluent was conducted to assess if the pits observed during normal testing exposures (65-74 hours) would grow at extended times. A single test cell was set up with three A537 immersion coupons (A537CL1-46, A537CL1-47, and A537CL1-48, see Appendix I for individual corrosion rates). The test solution was the uninhibited effluent for $\mathrm{H}$-area sludge dissolved with $2.5 \% \mathrm{OA}$. This solution was from the same batch of effluent used for Batch 1 in the test results described above. The testing was conducted for 288 hours at $50{ }^{\circ} \mathrm{C}$.

Pit measurements were made on coupons A537CL1-46 and A537CL1-47 from the 288-hour test. Pit measurements were also made for comparison on two coupons from the shorter testing described above, A537CL1-49 (exposed 74 hours) and A537CL1-52 (exposed 65 hours) that were exposed to the uninhibited effluent from decomposition of $2.5 \%$ OA dissolved $\mathrm{H}$-area and F-area sludge, respectively. The data is summarized in Table 4.4-3 which shows the average pit depth to be less than 1 mil although depths had wide ranges with depths greater than $1 \mathrm{mil}$ for the longer exposure time. At a 95\% confidence level, the coupons exposed for 288 hours had average pit depths that were statistically different from one another and those coupons exposed for shorter time. There was no statistical difference from the two coupons exposed for the shorter times to the H-area and F-area based effluents.

Table 4.2-3 Pit Measurements in Uninhibited Effluent from Decomposition of 2.5\% OA Dissolved H-area and F-area Sludge

\begin{tabular}{|c|c|c|c|c|c|c|}
\hline Coupon & Sludge & Time & Average (mil) & Standard Deviation & $\mathbf{N}$ & Range \\
\hline A537CL1-46 & H-area & 288 & 0.647 & 0.29 & 31 & $0.24-1.34$ \\
\hline A537CL1-47 & H-area & 288 & 0.904 & 0.347 & 24 & $0.37-1.53$ \\
\hline A537CL1-49 & H-area & 74 & 0.358 & 0.21 & 25 & $0.13-0.68$ \\
\hline A537CL1-52 & F-area & 65 & 0.338 & 0.106 & 32 & $0.18-0.56$ \\
\hline
\end{tabular}

\subsection{UNINHIBITED EFFLUENT - 1\% OXALIC ACID}

This testing was conducted in effluents generated with three different UV light conditions (no UV, clean UV, and dirty UV) in the destruction loop. This testing was conducted prior to the $2.5 \%$ OA testing, which did not use the UV light. During this phase of testing, the electrochemical tests were performed such that CPP was conducted at the end of each batch. The correlation of the electrochemical data with the immersion coupon data is more difficult since the surface of the electrochemical coupons become altered from performing the CPP. The performance of the CPP had no effect on the immersion coupons.

The A537 immersion coupons exposed to uninhibited effluent from the decomposition of the OA dissolved F-area sludge were covered with an adherent corrosion product that varied in coloring (black/blue, rust and brown) and covered at least $60 \%$ of the surface area. The 304L immersion coupons appeared to have a light surface stain or a residue of ferric/ferrous oxide from the solution or carbon steel corrosion. Figure 4.3-1 shows the paired 304L and A537 
immersion coupons that were exposed to the uninhibited F-area based effluent when no UV light was used during the OA decomposition.

The A537 immersion coupons exposed to uninhibited effluent from the decomposition of OA dissolved $\mathrm{H}$-area sludge had the corrosion products primarily on the edge while the face of the coupons had less than 30\% coverage by corrosion products. The 304L immersion coupons had a fairly uniform rust color staining across the surface. Figure 4.3-2 shows the paired 304L and A537 immersion coupons that were exposed to the uninhibited H-area based effluent when no UV light was used during the OA decomposition.

After cleaning the immersion coupons, the A537 coupons were found to have pitted as shown by the photographs in Figure 4.3-3, which displays the as-received and as-cleaned photographs of coupon A537CL1-35 and a 10x stereomicroscope view of the coupon. A537CL1-35 was exposed to uninhibited effluent that came from a clean UV light decomposition of an OA dissolved F-area sludge.

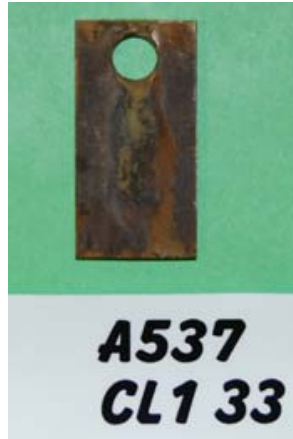

(A)

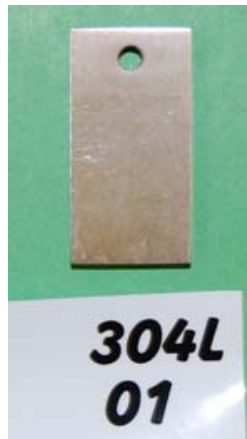

(B)

Figure 4.3-1 Immersion coupons exposed to uninhibited effluent from decomposition of 1 \% OA dissolved F-area sludge and no UV light during destruction: (A) A537CL1-33 and (B) 304L-01.

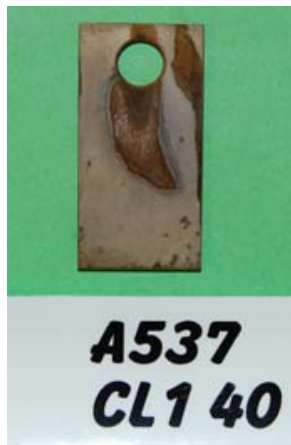

(A)

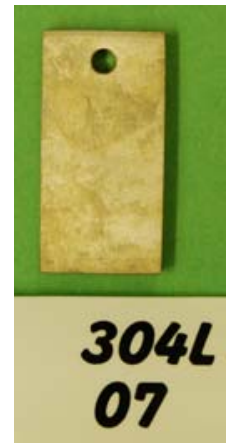

(B)

Figure 4.3-2 Immersion coupons exposed to uninhibited effluent from decomposition of 1 \% OA dissolved $\mathrm{H}$-area sludge and no UV light during destruction: (A) A537CL1-40 and (B) 304L-07. 


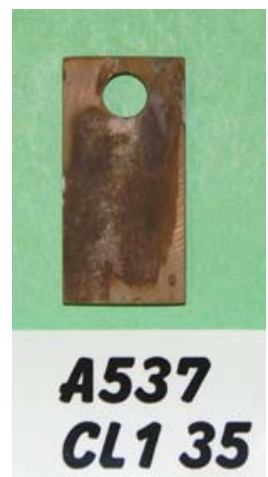

(A)

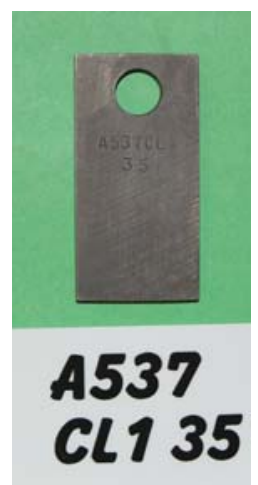

(B)

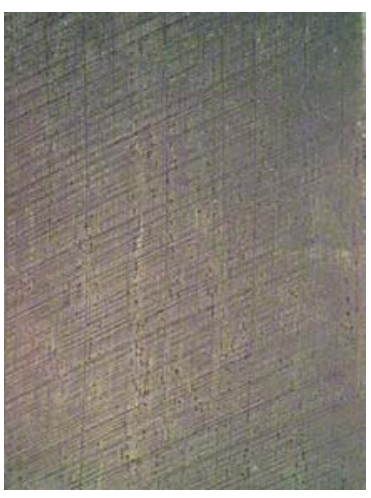

(C)

Figure 4.3-3 Photographs of immersion coupon, A537CL1-35, exposed to uninhibited effluent from decomposition of $1 \%$ OA dissolved F-area sludge and using a clean UV light: (A) as-received; (B) as-cleaned; (C) 10x stereomicroscope view.

On the as-cleaned coupon, vertical markings run the length of coupon, which cross the initial grinding marks that are somewhat diagonal on the coupon. In the stereomicroscope view, these markings can be seen to be linear arrays of pits. The pits measured less than 1 mil (0.001 in). These types of arrays were observed on all the A537 coupons. The grinding marks on the smoother backside of all the coupons were no longer observable. The 304L immersion coupons had a shiny metallic finish with no corrosion except some coupons had some residual stains.

The weight changes and corrosion rates for each immersion coupon are given in Appendix 1. The average corrosion rates for the A537 and 304L immersion coupons for each test condition are given in Table 4.3-1. The no-light condition gave the highest corrosion rates for A537 immersion coupons in both types of sludge, although all the corrosion rates for all light conditions are close for each type of sludge.

Table 4.3-1 Average Corrosion Rates of A537 and 304L Immersion Coupons in Uninhibited Effluents - 1\% OA Sludge Dissolution

\begin{tabular}{|c|c|c|c|}
\hline \multirow{2}{*}{ Sludge } & \multirow{2}{*}{ Light Condition } & \multicolumn{2}{|c|}{ Corrosion Rate (mpy) } \\
\cline { 3 - 4 } & A537 & 304L \\
\hline F-area & No light & 19.6 & 0.67 \\
\hline & Clean light & 12.4 & 0.68 \\
\hline & Dirty light & 15 & 0.66 \\
\hline H-area & No light & 9.1 & 0.71 \\
\hline & Clean light & 8.4 & 0.69 \\
\hline & Dirty light & 6.4 & 0.67 \\
\hline
\end{tabular}

The corrosion rates for the F-area sludge were greater than those measured for the $\mathrm{H}$-area sludge. The corrosion rates for 304L were all less than 1 mpy and not dependent on the 
exposure condition. Corrosion rates less than 2 mpy are considered excellent while rates from 2 to 20 mpy are considered good [26].

The electrochemical coupons were all highly corroded due to the CPP curves performed at the end of each batch. The coupons were pitted with measured pits ranging in size from less than 1 mil to 7 mils. The final instantaneous corrosion rates and OCP values for each batch are given in Table 4.3-2 for all the electrochemical coupons (as well as in Appendix II). The shaded data is suspect for either questionable measurements or uncertainty about the test coupon. Average values for the Batch 1 and Batch 3 data are given for ease of comparison. Except for a few coupons, the corrosion rates are fairly uniform for each batch. The different sludges and light conditions did not have a significant effect on the corrosion rate. In general, these instantaneous corrosion rates were lower than those measured by weight loss.

The corrosion rate for a coupon over the course of exposure during Batch 1 usually decreased while the OCP was raised towards more noble values (less negative). On subsequent batches the corrosion rates generally decreased but not as much as during Batch 1. OCP values generally became less negative but sometime no change or becoming more negative was observed. The changes during Batch 1 were most consistent.

Table 4.3-2 Electrochemical Measurements in Uninhibited Effluent - 1\% OA Sludge Dissolution

\begin{tabular}{|c|l|l|l|l|c|c|}
\hline \multirow{2}{*}{$\begin{array}{c}\text { Test } \\
\text { Condition }\end{array}$} & \multirow{2}{*}{$\begin{array}{c}\text { Coupon } \\
\text { Number }\end{array}$} & \multicolumn{2}{c|}{ Corrosion Rate (mpy), OCP (mV) } & \multicolumn{2}{c|}{$\begin{array}{c}\text { Average Rate } \\
\text { (mpy) }\end{array}$} \\
\cline { 3 - 7 } & & \multicolumn{1}{|c|}{ Batch 1 } & \multicolumn{1}{c|}{ Batch 2 } & \multicolumn{1}{c|}{ Batch 3 } & Batch 1 & Batch 3 \\
\hline F-area, NL & EC-A537-8 & $1.85,-580$ & $4.68,-438$ & $9.14,-339$ & 2.7 & 7.2 \\
\hline & EC-A537-5 & $3.49,-641$ & $5.46,-436$ & $5.21,-328$ & & \\
\hline F-area, CL & EC-A37-1 & $5.84,-642$ & $8.36,-423$ & $6.25,-251$ & 6.9 & 6.3 \\
\hline & EC-A537-2 & $8,-618$ & $8.59,-349$ & $6.37,-297$ & & \\
\hline F-area, DL & EC-A537-3 & $7.29,-645$ & $5.36,-459$ & $6.88,-388$ & 7.8 & 7.4 \\
\hline & EC-A537-4 & $8.37,-641$ & $6.9,-444$ & $7.95,-347$ & & \\
\hline H-area, NL & EC-A537-6 & $93,-615$ & $6.6,-315$ & $8.3,-414$ & 5.8 & 8.9 \\
\hline & EC-A537-7 & $5.8,-581$ & $10.3,-349$ & $9.48,-412$ & & \\
\hline H-area, CL & EC-A537-9 & \multicolumn{1}{c}{ ND } & $11.6,-269$ & $11.3,-352$ & ND & 7.7 \\
\hline & EC-A537-10 & $2,-306$ & ND & $4.07,-654$ & & \\
\hline H-area, DL & EC-A537-11 & $2.37,-489$ & $8,-237$ & $9,86,-365$ & 2.1 & 6 \\
\hline & EC-A537-12 & $1.9,-445$ & $3 .,-221$ & $2.18,-215$ & & \\
\hline
\end{tabular}

The CPP scans for the two sludges differed slightly with uninhibited F-area based effluents showing anodic dissolution with some propensity for pitting while uninhibited H-area based effluents showed slight passivity behavior to pitting breakdown. Figure 4.3-4 shows these curves for the no light and clean light conditions for both the F-area and H-area base effluents. The positive hysteresis shown in the figure is indicative of pitting. The H-area based effluents also displayed a jump in the corrosion potential (Ecorr) from values between -600 and $-650 \mathrm{mV}$ (see Batch 1 OCP data in Table 4.3-2) to values between -300 to $-500 \mathrm{mV}$ (note potentials in Figure 4.3-4). 
The effluent chemistry was characterized by the $\mathrm{pH}$, ORP, residual OA concentration and specific metal concentrations of $\mathrm{Al}, \mathrm{Fe}, \mathrm{Mn}, \mathrm{Ni}$, and Hg. The ORP was measured during the test, while the remaining parameters were measured at the conclusion of testing. The effluent chemistries for the F- and H-area sludges were similar as shown by the data in Table 4.3-3 for the no light condition. Only the Hg concentration is shown since the other metals would not impact the corrosion. The other metals except $\mathrm{Na}$ and $\mathrm{Al}$ were all less than $1 \mathrm{ppm}$. Al concentrations ranged from 19.3 to less than 1 ppm for F-area sludge and 1.6 to less than 1 ppm for $\mathrm{H}$-area sludge. The chemistries for the clean and dirty light conditions were similar to those for the no light condition.

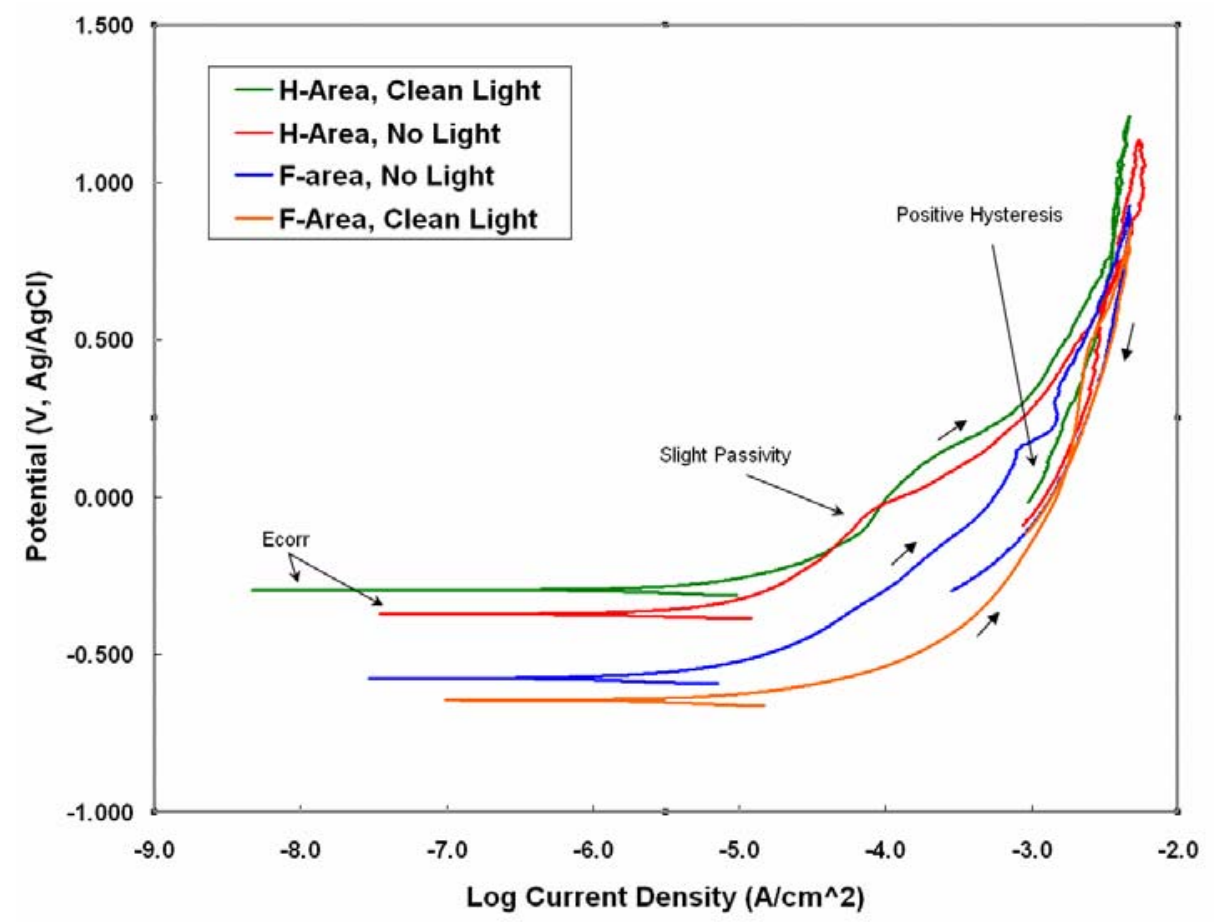

Figure 4.3-4 CPP scans from Batch 1 in uninhibited effluent from the destruction loop with clean and no light conditions using F-area and $\mathrm{H}$-area sludge dissolved by $1 \%$ OA. Arrows indicate direction of scan.

Table 4.3-3 Effluent Chemistry Parameters Measured For Uninhibited (No Light) Effluent - 1\% OA Sludge Dissolution

\begin{tabular}{|c|c|c|c|c|c|}
\hline Sludge & Batch & pH & ORP (mV) & OA (ppm) & Hg (ppm) \\
\hline F-area & 1 & 8.8 & 173 & 14 & 0.1 \\
\hline & 2 & 7.6 & 225 & 18 & 0.5 \\
\hline & 3 & 7.6 & 340 & 9 & 0.2 \\
\hline H-area & 1 & 8.9 & 167 & 14 & 1.14 \\
\hline & 2 & 8.4 & 326 & 18 & 0.36 \\
\hline & 3 & 8.5 & 243 & 14 & 0.26 \\
\hline
\end{tabular}




\subsection{EFFLUENT UNDER CORROSION CONTROL - 2.5\% OXALIC ACID}

The results for the effluent under corrosion control are presented by the AREVA grouping of the different corrosion control scenarios for testing. The groupings were by the type of sludge and the use of evaporation. A summary test description for each AREVA task number is shown below.

- 1-F - F-area sludge, effluent combined with supernate or hydroxide, no evaporator

- 1-H - H-area sludge, effluent combined with supernate or hydroxide, no evaporator

- 2-F - F-area sludge, effluent with and without hydroxide, evaporator

- 2-H - H-area sludge, effluent with and without hydroxide, evaporator

The corrosion tests for this phase of testing were set up so the coupons were exposed to three batches of destruction loop effluent from sequential OA strikes on a sludge. The exposure period for the first two batches were for approximately 18 hours while the exposure period for the third batch was 7 days. 304L immersion coupons were not tested.

\subsubsection{F-Area Sludge with Supernate or Hydroxide and No Evaporation}

These test results are for cases $1 \mathrm{~A}, 1 \mathrm{~B}$, and 3 as given in Table 3.2-2. Both the immersion and electrochemical A537 coupons did not have a build up of corrosion products after an exposure time of 219 hours. The coupons had a dulled grey metallic appearance as shown by the photographs in Figure 4.4.1-1 for coupons from case 1A. On a macroscopic level, the immersion coupons appeared to have had minimal degradation with a few sites of possible pitting as indicated by small areas of corrosion products. These areas were on the smooth side of the coupon only. The electrochemical samples had no macroscopic indications of pitting.

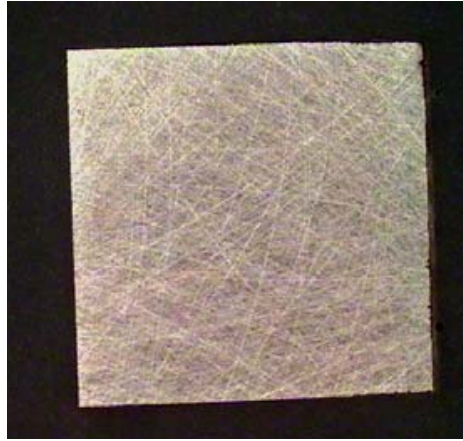

(A)

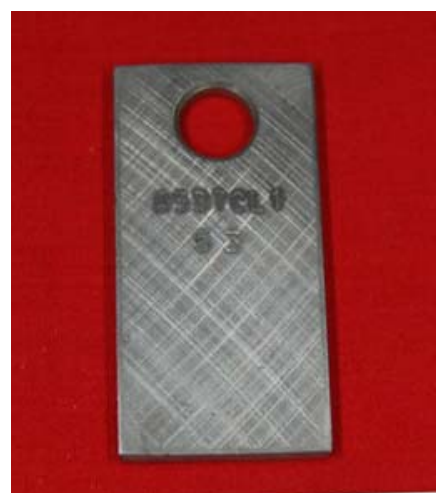

(B)

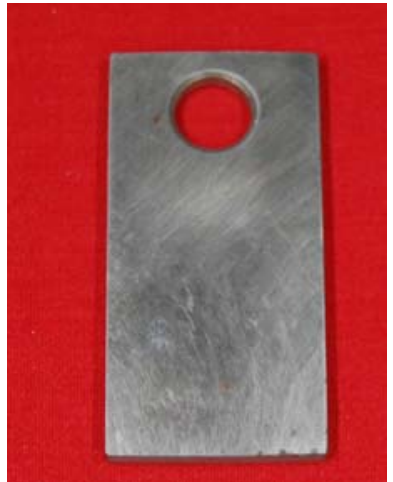

(C)

Figure 4.4.1-1 Corrosion coupons - Case 1A - low magnification: (A) electrochemical, EC-A537-16 and (B and C) immersion, A537CL1-53, front and back.

Upon microscopic examination both the electrochemical and immersion coupons were found to have pitted. Figure 4.4.1-2 shows higher magnification photographs for the coupons shown in Figure 4.4.1-1. For the electrochemical coupon, the hemispherical pits were less than 1 mil in width and were associated with areas of breakdown surrounding them. For test 
case $1 \mathrm{~B}$, the pits were clearly defined without surrounding areas of breakdown and grew uniformly across the surface. For case 3, the coupons did not pit, but had localized areas of breakdown, which were not hemispherical. A hemispherical shape is more indicative of pitting while small irregular areas are considered non-uniform localized corrosion. For the immersion coupons, pit depths were measured for one coupon from each test case. The pit depths were 1 mil or less. The pits appeared to form in linear arrays as shown in Figure 4.4.1-2.

The weight changes and corrosion rates for each immersion coupon are given in Appendix 1. The A537 immersion coupons had average corrosion rates of $0.39,0.38$ and 0.26 mpy for cases 1A, 1B, and 3, respectively. For case 1A, one coupon, A537CL1-53, had a corrosion rate $69 \%$ higher than the duplicate. For cases $1 \mathrm{~B}$ and 3 , the corrosion rates of the duplicate samples were in good agreement.

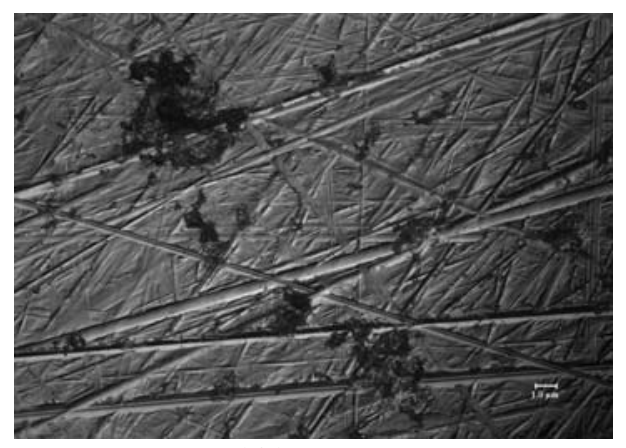

(A)

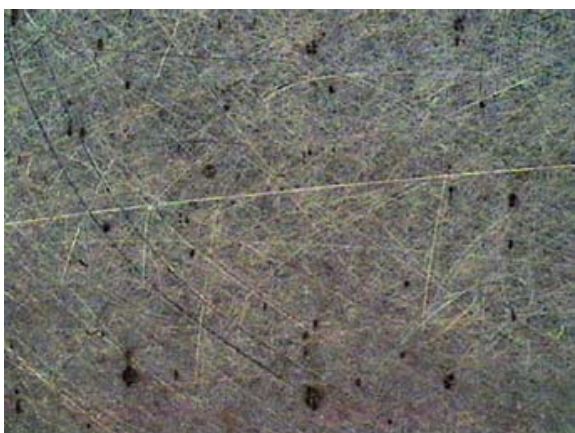

(B)

Figure 4.4.1-2 Corrosion coupons - Case 1A - high magnification: (A) electrochemical, EC-A537-16 and (B) immersion, A537CL1-53.

The OCP and instantaneous corrosion rates of the electrochemical coupons were variable over the course of the first two batches but stabilized over the week-long exposure of the third batch. The data are summarized in Table 4.4.1-1 which shows the OCP and last instantaneous corrosion rate measurement for each coupon. Appendix III gives the instantaneous corrosion rates for each electrochemical coupon at the start and end of each batch. The OCP values were all near $-100 \mathrm{mV}$; average corrosion rates for cases $1 \mathrm{~A}, 1 \mathrm{~B}$, and 3 were $1.77,0.17$, and 1.18 mpy, respectively. The electrochemical corrosion rates tended to be greater than the weight loss corrosion rates.

Table 4.4.1-1 Electrochemical Data for 1-F Series Coupons

\begin{tabular}{|c|c|c|c|}
\hline Coupon \# & Case & OCP (mV) & Corrosion Rate (mpy) \\
\hline EC-A537-16 & 1A & -103 & 0.66 \\
\hline EC-A537-17 & 1A & -109 & 2.87 \\
\hline EC-A537-18 & 1B & -144 & 0.13 \\
\hline EC-A537-19 & 1B & -92 & 0.25 \\
\hline EC-A537-20 & 3 & -119 & 1.86 \\
\hline EC-A537-36 & 3 & -118 & 0.5 \\
\hline
\end{tabular}


The CPP scans all showed passive behavior with passive current densities in the range of $10^{-6}$ to $10^{-5} \mathrm{~A} / \mathrm{cm}^{2}$. Figure 4.4.1-3 shows the CPP scans for duplicate test of case $1 \mathrm{~A}$. The CPP scans for the duplicate samples differed. As can be seen in the figure, one coupon has a welldefined anodic peak during the forward polarization scan. This peak is indicative of a transition in the oxide that formed on the coupon from a ferrous to a ferric form. The passive current densities after this change in oxide are higher, indicative of a less protective film. Coupon EC-A537-16 had a positive hysteresis for the entire reverse scan indicative of pitting while EC-A537-17 had a small positive hysteresis at the electropositive potentials only. Both samples were found to have pits. The CPP scans for cases $1 \mathrm{~B}$ and 3 also had a positive hysteresis at the electropositive potentials only.

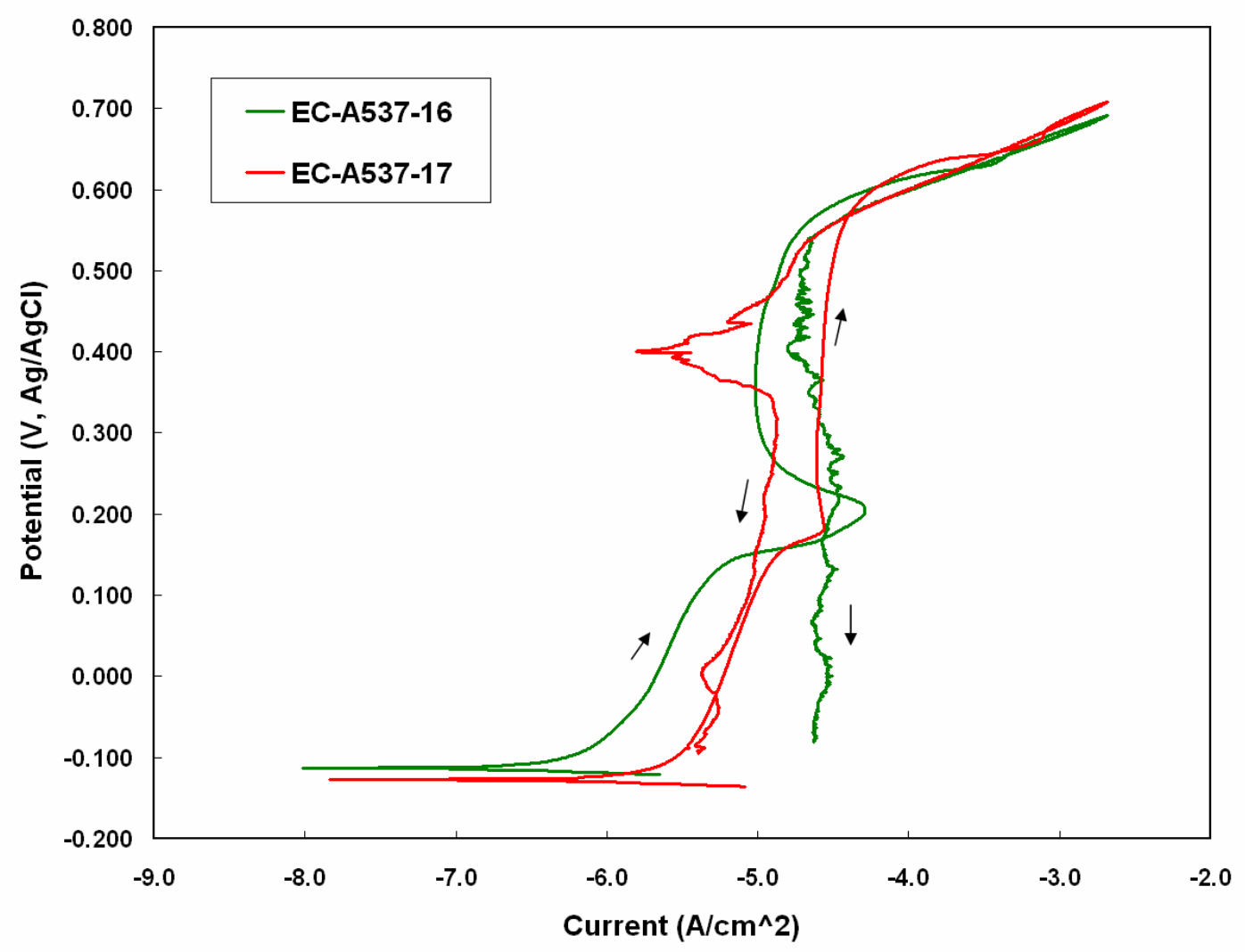

Figure 4.4.1-3 CPP scans for coupons EC-A537-16 and EC-A537-17 (Case 1A).

The effluent chemistry was characterized by the $\mathrm{pH}$, ORP, residual OA concentration and specific metal concentrations of $\mathrm{Al}, \mathrm{Fe}, \mathrm{Mn}, \mathrm{Ni}$, and $\mathrm{Hg}$. The ORP was measured during the test, while the remaining parameters were measured at the conclusion of testing. The effluent chemistry is shown in Table 4.4.1-2 and are the values prior to mixing with the supernate. Only the Hg concentration is shown since the other metals would not impact the corrosion. The other metals were less than $1 \mathrm{ppm}$. These values are similar to those observed previously for the uninhibited effluent from decomposition of the $2.5 \%$ dissolved sludges (see Table 4.2-2) 
Table 4.4.1-2 Effluent Chemistry Parameters Measured for F-area Based Effluent Mixed with Supernates

\begin{tabular}{|c|c|c|c|c|}
\hline Batch & pH & ORP (mV) & OA (ppm) & Hg (ppm) \\
\hline 1 & 8.3 & 243 & 36 & 2.24 \\
\hline 2 & 7.7 & 255 & 18 & 3.0 \\
\hline 3 & 7.8 & 482 & 18 & 2.45 \\
\hline
\end{tabular}

\subsubsection{H-Area Sludge with Supernate or Hydroxide and No Evaporation}

These test results are for cases 2A, $2 \mathrm{~B}$ and 4 as given in Table 3.2-2. The immersion and electrochemical A537 coupons did not have a build up of corrosion products after an exposure time of 229 hours. The immersion coupons had a dulled grey metallic appearance, whereas the electrochemical coupons had a stain or film on the surface. Figure 4.4.2-1 shows the coupons for case 2A. On a macroscopic level, the immersion coupons appeared to have had minimal degradation with a few sites of localized breakdown. The electrochemical samples had no indication of pitting.

After cleaning, the coupons were observed at higher magnification. The immersion coupons were found to have the grinding marks clearly observable. For cases $2 \mathrm{~A}$ and $2 \mathrm{~B}$, there were no pits, although some areas of localized breakdown as shown in Figure 4.4.2-2 (A). For case 4 , a couple of pits were found on each coupon. The pits tended to be angular, possibly associated with inclusions. The electrochemical coupons were all found to have pitting although coverage was variable but not correlated to the exposure conditions. Figure 4.4.2-2 (B) shows a 10X magnification of coupon EC-A537-23.

The weight changes and corrosion rates for each immersion coupon are given in Appendix 1. The A537 immersion coupons had average corrosion rates of $0.24,0.26$ and 0.20 mpy for cases $2 \mathrm{~A}, 2 \mathrm{~B}$, and 4 , respectively. For all cases, the corrosion rates of the duplicate samples were in good agreement.

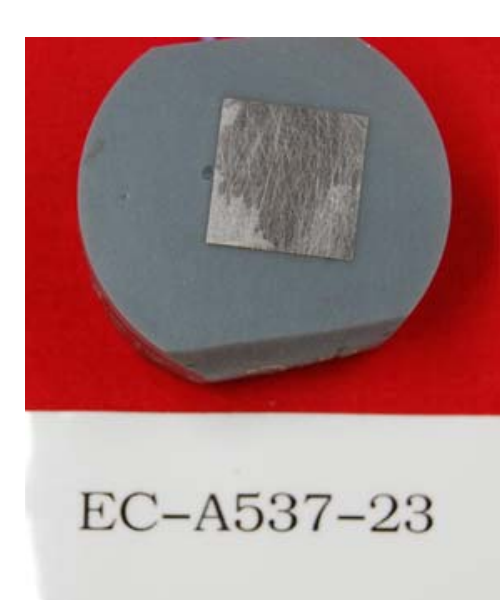

(A)

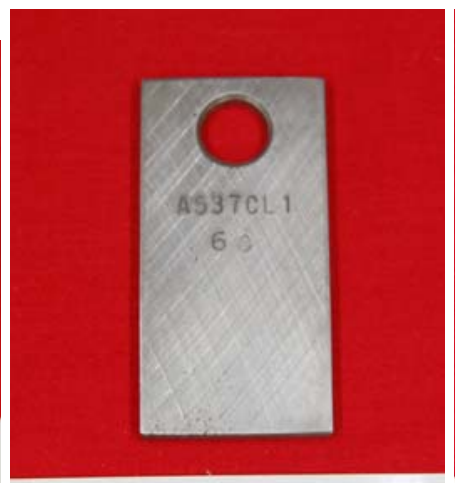

A537 CL1 60

(B)

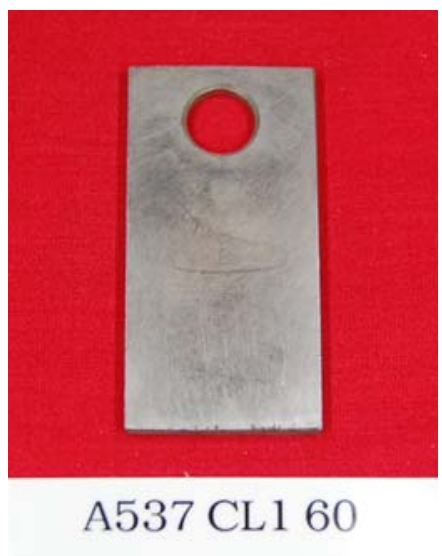

(C)

Figure 4.4.2-1 Corrosion coupons - Case 2A - low magnification: (A) electrochemical, EC-A537-23 and (B and C) immersion, A537CL1-60, front and back. 


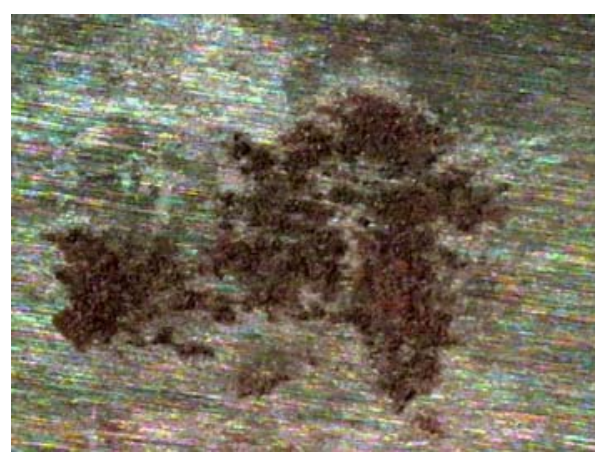

(A)

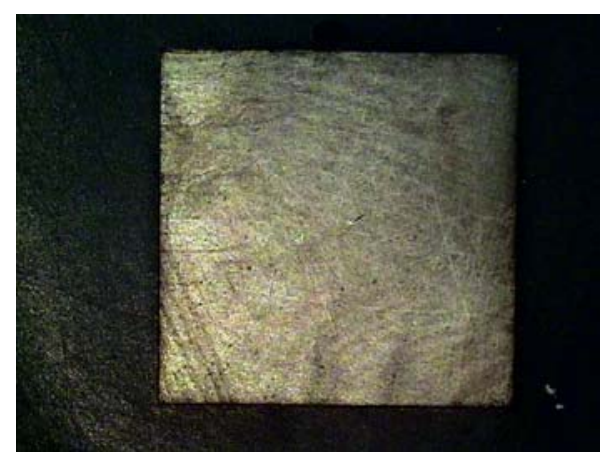

(B)

Figure 4.4.2-2 Corrosion morphology for Case 2A coupons: (A) immersion coupon A537CL1-60 showing localized breakdown, 60X; (B) electrochemical, ECA537-23, tiny pits across surface.

The OCP and instantaneous corrosion rates of the electrochemical coupons were variable over the course of the first two batches but stabilized over the week-long exposure of the third batch. The data are summarized in Table 4.4.2-1 which shows the OCP and last instantaneous corrosion rate measurement for each coupon. Appendix III gives the instantaneous corrosion rates for each electrochemical coupon at the start and end of each batch. The OCP final values were all near $-100 \mathrm{mV}$ after generally starting at more electronegative values (-200 to $-300 \mathrm{mV})$. The average corrosion rates for cases $2 \mathrm{~A}, 2 \mathrm{~B}$, and 4 were 1.18, 0.16, and $0.14 \mathrm{mpy}$, respectively. Except for case 2A, the electrochemical corrosion rates were equivalent to weight loss corrosion rates.

Table 4.4.2-1 Electrochemical Data for 1-H Series Coupons

\begin{tabular}{|c|c|c|c|}
\hline Coupon \# & Case & OCP (mV) & Corrosion Rate (mpy) \\
\hline EC-A537-22 & 2A & -99 & 1.48 \\
\hline EC-A537-23 & 2A & -99 & 0.88 \\
\hline EC-A537-24 & 2B & -120 & 0.12 \\
\hline EC-A537-25 & 2B & -142 & 0.19 \\
\hline EC-A537-26 & 4 & -94 & 0.11 \\
\hline EC-A537-27 & 4 & -96 & 0.16 \\
\hline
\end{tabular}

The CPP scans showed passive behavior with initial passive current densities in the range of $10^{-6}$ to $10^{-5} \mathrm{~A} / \mathrm{cm}^{2}$. Figure 4.4.2-3 shows a CPP scan for each case with the reverse curve truncated to simplify comparison. Similar to the test results in the F-area based solutions, an anodic peak was observed in the range of 0.2 to $0.4 \mathrm{~V}$, however, there was no difference observed between duplicate tests. Similar to case 1A with F-area based solutions, for case 2A one sample (EC-A537-22) had a positive hysteresis while the duplicate had a positive hysteresis only at electropositive potentials. This finding indicates the A537 has some susceptibility to pitting when the uninhibited effluent is mixed with the typical nitrate supernate, i.e. low inhibitor concentrations in this testing. 
The effluent chemistry was characterized by the $\mathrm{pH}$, ORP, residual OA concentration and specific metal concentrations of $\mathrm{Al}, \mathrm{Fe}, \mathrm{Mn}, \mathrm{Ni}$, and $\mathrm{Hg}$. The ORP was measured during the test, while the remaining parameters were measured at the conclusion of testing. The effluent chemistry is shown in Table 4.4.2-2 and these are the values prior to mixing with the supernate. Only the Hg concentration is shown since the other metals would not impact the corrosion. The other metals were less than $1 \mathrm{ppm}$. These parameters are similar to those reported in Table 4.2-2 for the 2.5\% OA-based effluent

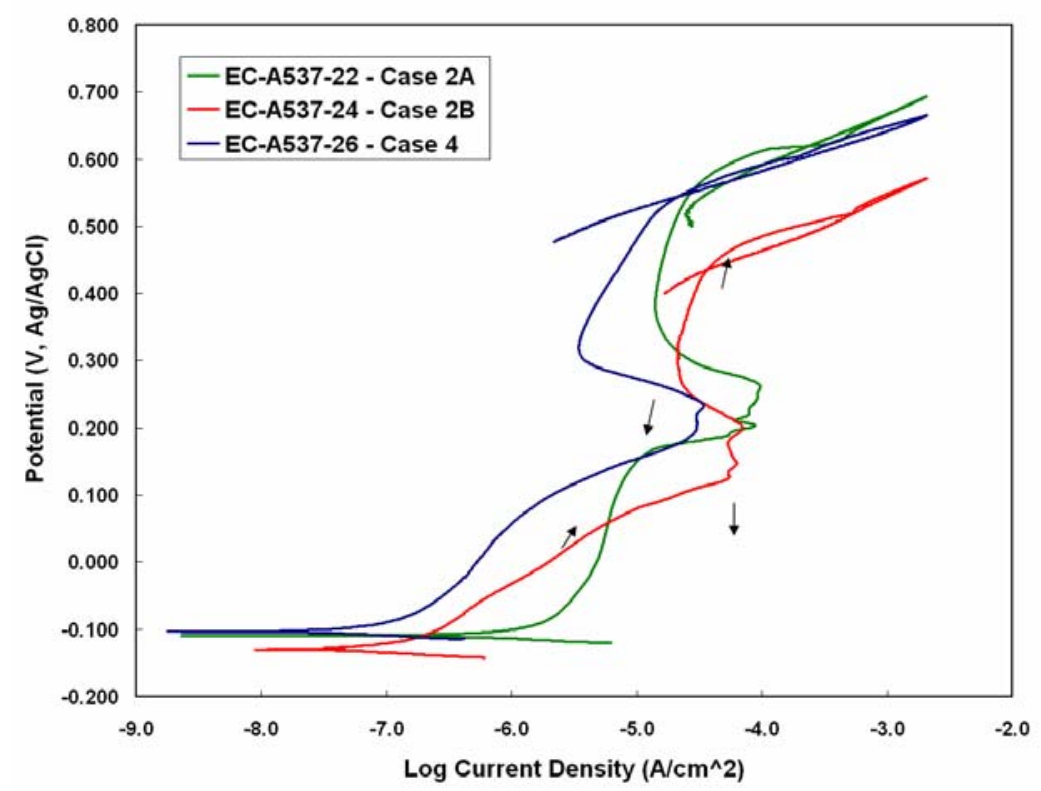

Figure 4.4.2-3 CPP scans for coupons EC-A537-22 (Case 2A), EC-A537-24 (Case 2B) and EC-A537-26 (Case 4). Reverse portion of the scan has been omitted for clarity.

Table 4.4.2-2 Effluent Chemistry Parameters Measured for H-area Based Effluent Mixed with Supernates

\begin{tabular}{|c|c|c|c|c|}
\hline Batch & pH & ORP (mV) & OA (ppm) & Hg (ppm) \\
\hline 1 & 8.3 & 273 & 50 & 1.66 \\
\hline 2 & 8.3 & 263 & 36 & 2.16 \\
\hline 3 & 8.0 & 331 & 32 & 2.12 \\
\hline
\end{tabular}

\subsubsection{F-Area Sludge with Evaporation}

These test results are for cases 5 and 7 described in Table 3.3.2, which include evaporation without or with hydroxide addition, respectively. The immersion and electrochemical A537 coupons did not have a build up of corrosion products after 290 hours of exposure. Both the electrochemical and immersion coupons had a dulled grey metallic appearance except for coupon EC-A537-28 which had a thin adherent layer on the surface as shown in Figure 4.4.31 (A) for coupons from case 5. On a macroscopic level, the immersion coupons appeared to have had minimal degradation with most of the corrosion apparent on the edges. Other than 
coupon EC-A537-28, the electrochemical coupons were similar to the immersion coupons in general appearance although two coupons, one from each case, had crevice corrosion.

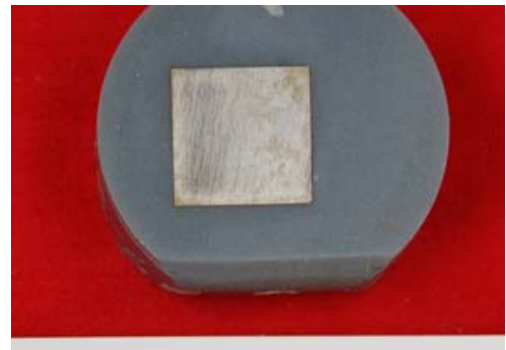

EC-A537-28

(A)

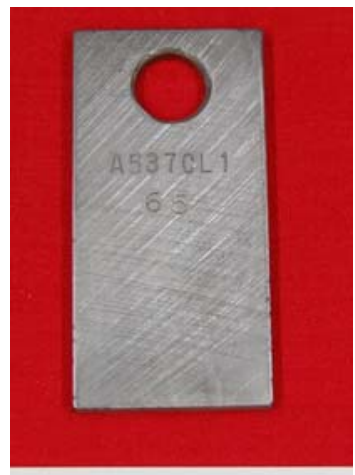

A537 CL1 65

(B)

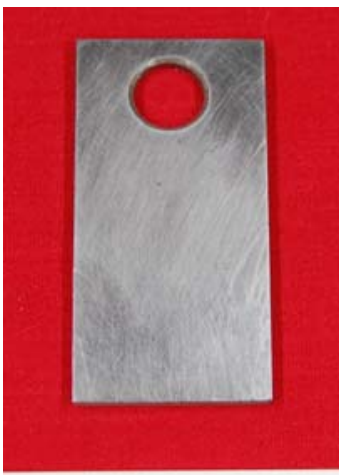

A537 CL1 65

(C)

Figure 4.4.3-1 Corrosion coupons - Case 5: (A) electrochemical, EC-A537-28; (B and C) immersion coupon, A537CL1-65, front and back.

After cleaning the coupons were observed at higher magnification. The electrochemical coupons had small pits or areas of localized corrosion as shown in Figure 4.4.3-2 that were either uniform across the surface or located near edges. The immersion coupons had one or two pits, either angular or hemispherical, on each coupon, but otherwise the coupons had minimal degradation with the grinding marks clearly observable as shown in Figure 4.4.3-2.

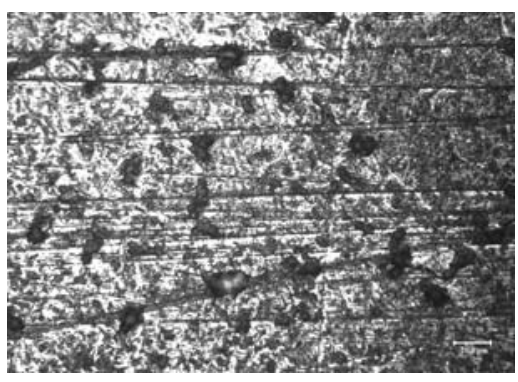

(A)

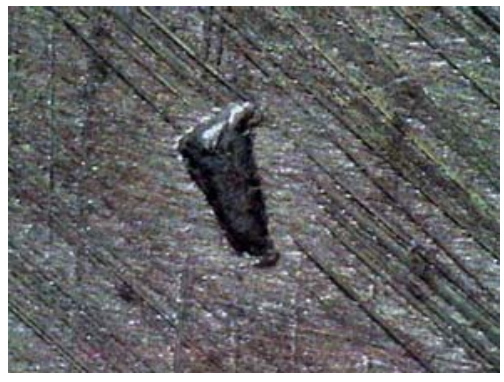

(B)

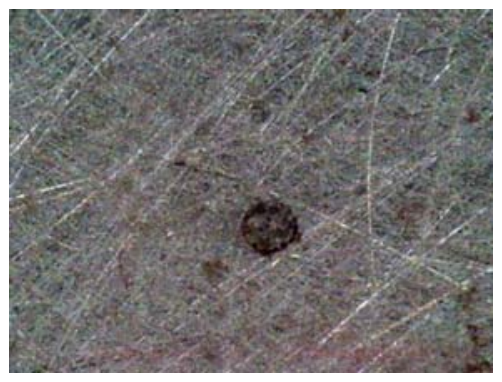

(C)

Figure 4.4.3-2 Corrosion morphology for cases 5 and 7 coupons: (A) electrochemical coupon, EC-A537-30, case 7; (B) immersion coupon, A537CL-66, case 5; and (C) immersion coupons, A537CL1-65, case 5.

The weight changes and corrosion rates for each immersion coupon are given in Appendix 1. The A537 immersion coupons had average corrosion rates of 0.16 mpy for both cases 5 and 7 , respectively. For all cases, the corrosion rates of the duplicate samples were in good agreement.

The OCP and instantaneous corrosion rates of the electrochemical coupons were variable over the course of the first two batches but stabilized over the week-long exposure of the third batch. The data are summarized in Table 4.4.3-1 which shows the OCP and last 
instantaneous corrosion rate measurement for each coupon. Appendix III gives the instantaneous corrosion rates for each electrochemical coupon at the start and end of each batch. The OCP final values were all near $-100 \mathrm{mV}$. The OCP values varied around -100 $\mathrm{mV}$ for the entire test. The average corrosion rates for cases 5 and 7 were 3.1 and $2.4 \mathrm{mpy}$, respectively, which were greater than those values measured by weight loss.

Table 4.4.3-1 Electrochemical Data for 2-F Series Coupons

\begin{tabular}{|c|c|c|c|}
\hline Coupon \# & Case & OCP (mV) & Corrosion Rate (mpy) \\
\hline EC-A537-28 & 5 & -100 & 2.8 \\
\hline EC-A537-35 & 5 & -124 & 3.4 \\
\hline EC-A537-30 & 7 & -100 & 3.1 \\
\hline EC-A537-31 & 7 & -122 & 1.6 \\
\hline
\end{tabular}

The CPP scans for both cases were similar, displaying passive behavior as shown in Figure 4.4.3-3 for the case 5 electrochemical coupons. There is a slight positive hysteresis in the potential range of 0.5 to $0.7 \mathrm{~V}$, which may be associated with the pitting observed on the electrochemical coupons. EC-A537-31 displayed an anodic peak at a potential of approximately $0.0 \mathrm{~V}$, which differed from the duplicate coupon for case 5, EC-A537-30. Similar results were observed for the two case 7 tests. All the curves had similar passive current density in the range of $10^{-5}$ to $10^{-4} \mathrm{~A} / \mathrm{cm}^{2}$.

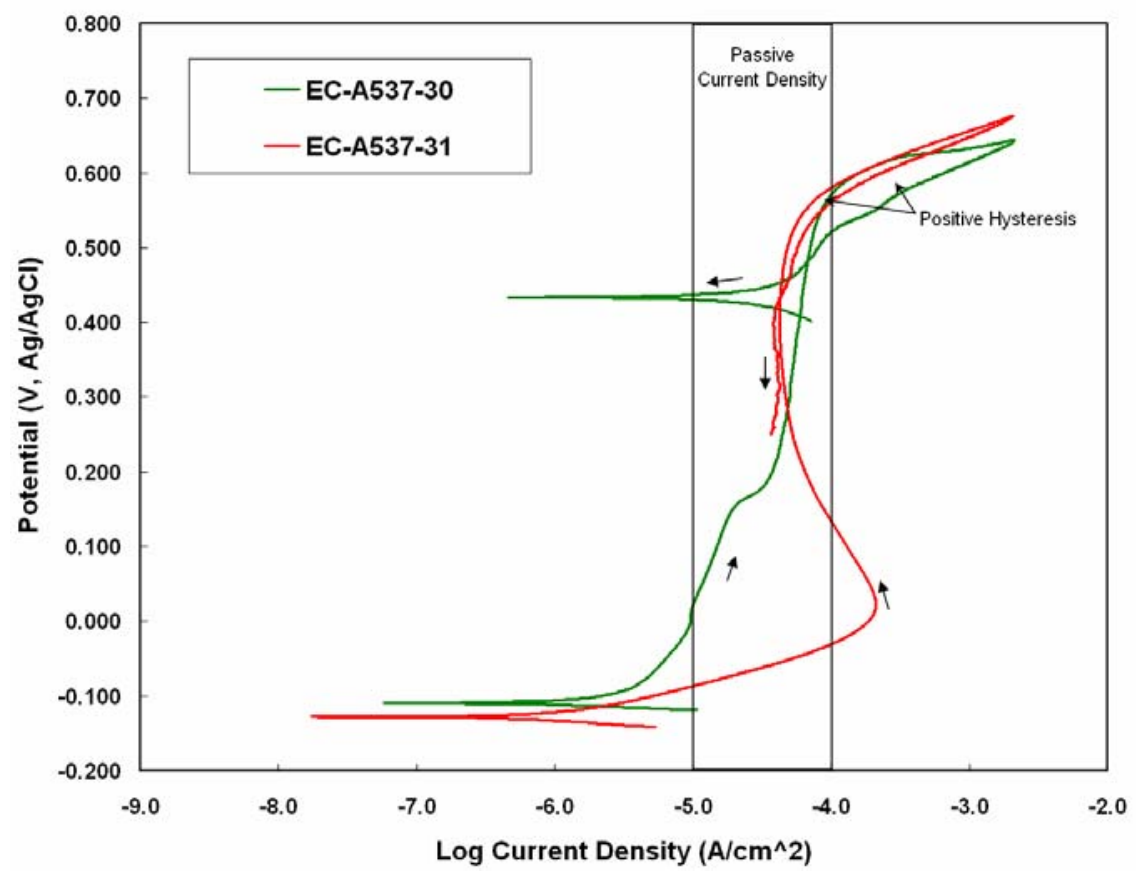

Figure 4.4.3-3 CPP scans for coupons EC-A537-30 and EC-A537-31 (Case 7). Reverse portion of the scan has been omitted for clarity.

The effluent chemistry was characterized by the $\mathrm{pH}$, ORP, residual OA concentration and specific metal concentrations of $\mathrm{Al}, \mathrm{Fe}, \mathrm{Mn}, \mathrm{Ni}$, and $\mathrm{Hg}$. The ORP was measured during the 
test, while the remaining parameters were measured at the conclusion of testing. The effluent chemistry is shown in Table 4.4.3-2 and these are the values prior to mixing with the supernate. Only the Hg concentration is shown since the other metals would not impact the corrosion. The other metals were less than $1 \mathrm{ppm}$ except aluminum was approximately 10 ppm. All values were trending higher than those observed for the corrosion controlled nonevaporated 2.5\% based effluent (See Tables 4.4.1-2 and 4.4.2-2).

Table 4.4.3-2 Effluent Chemistry Parameters Measured for F-area Based Effluent Mixed with Evaporation

\begin{tabular}{|c|c|c|c|c|}
\hline Batch & pH & ORP (mV) & OA (ppm) & Hg (ppm) \\
\hline 1 & 10.1 & 300 & 1990 & 6.1 \\
\hline 2 & 9.9 & 306 & 720 & 3.55 \\
\hline 3 & 9.6 & 512 & 225 & 2.40 \\
\hline
\end{tabular}

\subsubsection{H-Area Sludge with Evaporation}

These test results are for cases 6 and 8 described in Table 3.3.2, which include evaporation without or with an hydroxide addition, respectively. The immersion and electrochemical A537 coupons did not have a build up of corrosion products after 282 hours of exposure. Both the electrochemical and immersion coupons had a dulled grey metallic appearance. The electrochemical coupons had a small amount of crevice corrosion at the edges, but no significant areas of breakdown as shown in Figure 4.4.4-1 (A) for coupon EC-A537-37 (case 8). On a macroscopic level, the immersion coupons appeared to have had minimal degradation overall with a few areas of breakdown as shown by coupon A537CL1-02 in Figure 4.4.4-1 (B and C).

After cleaning, the coupons were observed at higher magnification. The electrochemical coupons showed pitting with areas of localized breakdown as shown in Figure 4.4.4.-2 (A) for coupon EC-A537-32 (case 6). The pitting was generally found closer to the edges near the crevice corrosion and areas of localized breakdown were more uniformly located across the surface. On the immersion coupons, the grinding marks were clearly observable. Areas of breakdown were found to have pitting associated with them, except for the case 8 coupon which had no pits. Figure 4.4.4-2 (B) shows an area of localized breakdown and associated pitting on coupon A537CL1-69 (case 6).

The weight changes and corrosion rates for each immersion coupon are given in Appendix 1. The A537 immersion coupons for case 6 had an average corrosion rate of 0.33 mpy. For case 8, one of the coupons, A537CL1-01, had a weight gain and was also the coupon that had no pitting. The other case 8 coupon, A537CL1-02, had a corrosion rate of 0.21 mpy. 


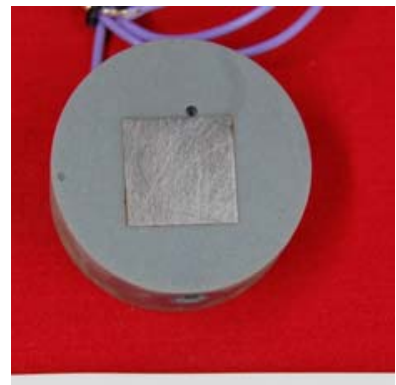

EC-A537-37

(A)

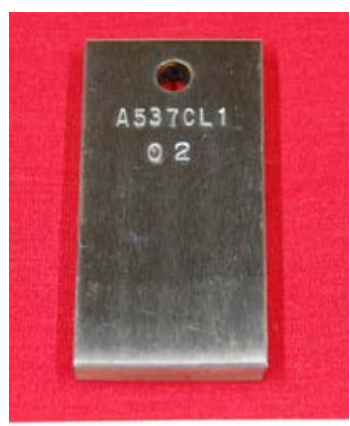

A537 CL 102

(B)

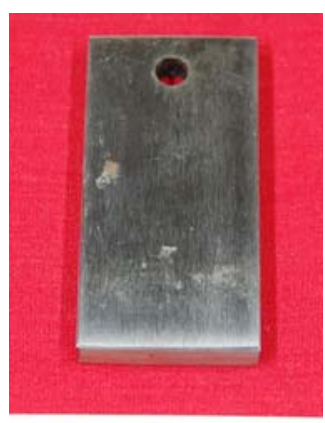

A537 CL1 02

(C)

Figure 4.4.4-1 Corrosion coupons - Case 8: (A) electrochemical, EC-A537-37; (B and C) immersion coupon, A537CL1-02, front and back.

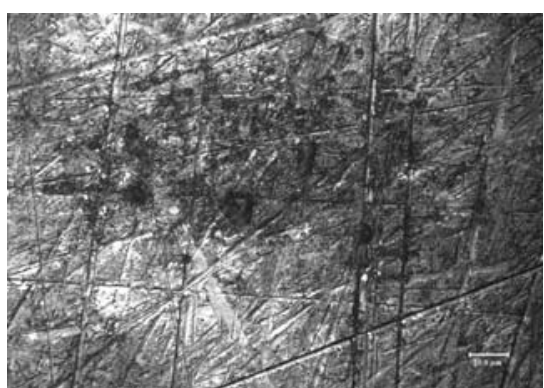

(A)

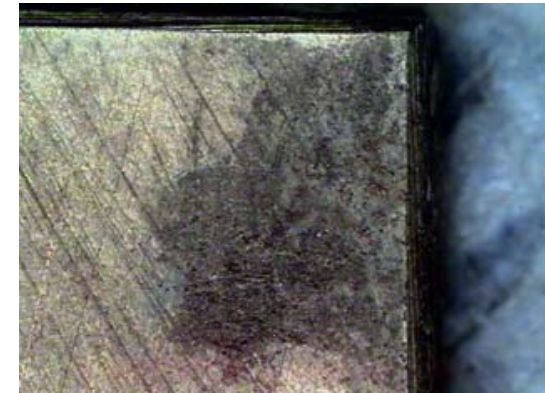

(B)

Figure 4.4.4-2 Corrosion morphology for case 6 coupons: (A) electrochemical coupon, ECA537-32 and (B) immersion coupon, A537CL-69.

The OCP and instantaneous corrosion rates of the electrochemical coupons were variable over the course of the first two batches but stabilized over the week-long exposure of the third batch. The data are summarized in Table 4.4.4-1 which shows the OCP and last instantaneous corrosion rate measurement for each coupon. Appendix III gives the instantaneous corrosion rates for each electrochemical coupon at the start and end of each batch. The OCP final values were all slightly less than $-100 \mathrm{mV}$, which they approached over the course of the three strikes. The average corrosion rates for cases 6 and 8 were 1.8 and 2.1 mpy, respectively, which were greater than those values measured by weight loss.

Table 4.4.4-1 Electrochemical Data for 2-H Series Coupons

\begin{tabular}{|c|c|c|c|}
\hline Coupon \# & Case & OCP (mV) & Corrosion Rate (mpy) \\
\hline EC-A537-32 & 6 & -89 & 2.6 \\
\hline EC-A537-38 & 6 & -84 & 1.0 \\
\hline EC-A537-34 & 8 & -96 & 1.4 \\
\hline EC-A537-37 & 8 & -92 & 2.8 \\
\hline
\end{tabular}

The CPP scans differed slightly for the two cases. For case 6 the scans indicated a susceptibility to pitting by the positive hysteresis observed on the reverse scan as shown in 
Figure 4.4.4-3. For case 8, the curves displayed an anodic passivation peak at approximately $0.0 \mathrm{~V}$ with a small positive hysteresis at high potentials $(550-700 \mathrm{mV})$. Both of these coupons were observed to have pits and areas of localized breakdown. The reverse scans were truncated for this figure to facilitate data comparison. For both cases, the passive current density was approximately $10^{-5}$ to $10^{-4} \mathrm{~A} / \mathrm{cm}^{2}$.

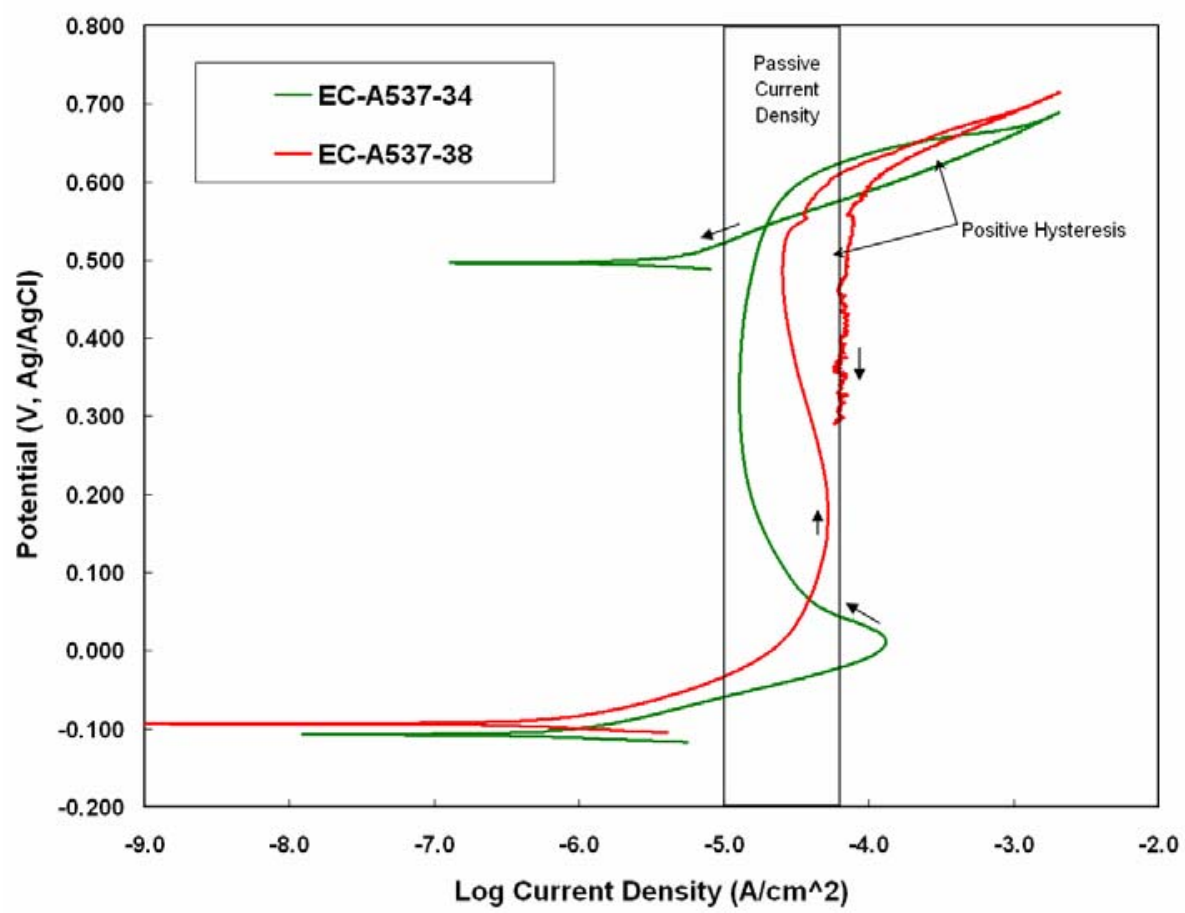

Figure 4.4.4-3 CPP scans for coupons EC-A537-34 (case 8) and EC-A537-38 (case 6). The reverse scans were truncated for clarity.

The effluent chemistry was characterized by the $\mathrm{pH}$, ORP, residual OA concentration and specific metal concentrations of $\mathrm{Al}, \mathrm{Fe}, \mathrm{Mn}, \mathrm{Ni}$, and Hg. The ORP was measured during the test, while the remaining parameters were measured at the conclusion of testing. The effluent chemistry is shown in Table 4.4.4-2 and these are the values prior to mixing with the supernate. Only the Hg concentration is shown since the other metals would not impact the corrosion. Aluminum was less than $5 \mathrm{ppm}$ and the other metals were less than $1 \mathrm{ppm}$. These values were higher than those observed for the corrosion controlled non-evaporated $2.5 \%$ OA based effluent (See Tables 4.4.1-2 and 4.4.2-2).

Table 4.4.4-2 Effluent Chemistry Parameters Measured for F-area Based Effluent Mixed with Evaporation

\begin{tabular}{|c|c|c|c|c|}
\hline Batch & pH & ORP (mV) & OA (ppm) & Hg (ppm) \\
\hline 1 & 10.1 & 460 & 2098 & 2.08 \\
\hline 2 & 9.5 & 303 & 1531 & 1.24 \\
\hline 3 & 8.7 & 504 & 671 & 0.68 \\
\hline
\end{tabular}




\subsection{DISCUSSION}

The corrosion impact of the ECC effluent on the deposition waste tank is of concern for the general rate of corrosion, as determined by weight loss, and the occurrence of localized corrosion since this information will be used to bound conditions for hydrogen and total gas generation and the structural integrity of the deposition tank during the ECC process. These items are safety class functions. The weight-loss corrosion rates measured with immersion coupons, the instantaneous corrosion rates measured with electrochemical coupons, and an indication of pitting are summarized in Table 5-1. The table shows that the two corrosion rate measurement were in reasonable agreement. The pitting susceptibility shown in the table indicates if carbon steel would pit under these conditions but is not an indication of sustained growth as shown by the data gathered during the ECC-HST testing.

Table 5-1 Summary of Average Corrosion Rates of A537 Carbon Steel in ECC-HST Test Solutions at $50{ }^{\circ} \mathrm{C}$

\begin{tabular}{|c|c|c|c|c|c|c|}
\hline \multirow{2}{*}{ Solution } & \multirow{2}{*}{$\begin{array}{c}\text { Oxalic } \\
\text { Acid (\%) }\end{array}$} & \multirow{2}{*}{$\begin{array}{l}\text { Light* } \\
\text { Condition }\end{array}$} & \multirow{2}{*}{ Sludge } & \multicolumn{2}{|c|}{ Corrosion Rate (mpy)** } & \multirow{2}{*}{$\begin{array}{c}\text { Pitting } \\
\text { Probable }\end{array}$} \\
\hline & & & & Immersion & Electrochemical & \\
\hline \multirow{6}{*}{$\begin{array}{c}\text { Uninhibited } \\
\text { Effluent }\end{array}$} & \multirow{6}{*}{1} & \multirow{2}{*}{ NL } & F-area & 19.6 & 7.2 & Yes \\
\hline & & & H-area & 9.1 & 8.9 & Yes \\
\hline & & \multirow{2}{*}{ DL } & F-area & 15 & 7.4 & Yes \\
\hline & & & H-area & 6.4 & 7.7 & Yes \\
\hline & & \multirow{2}{*}{ CL } & F-area & 12.4 & 6.3 & Yes \\
\hline & & & H-area & 8.4 & 6 & Yes \\
\hline \multirow{2}{*}{$\begin{array}{c}\text { Uninhibited } \\
\text { Effluent }\end{array}$} & \multirow{2}{*}{2.5} & \multirow{2}{*}{ NL } & F-area & 13.6 & 4.4 & Yes \\
\hline & & & H-area & 8.4 & 4.4 & Yes \\
\hline Case 1A & 2.5 & NL & F-area & 0.39 & 1.77 & Yes \\
\hline Case 1B & 2.5 & NL & F-area & 0.38 & 0.17 & No \\
\hline Case 2A & 2.5 & NL & H-area & 0.24 & 1.18 & Yes \\
\hline Case 2B & 2.5 & NL & H-area & 0.26 & 0.16 & No \\
\hline Case 3 & 2.5 & NL & F-area & 0.26 & 0.18 & No \\
\hline Case 4 & 2.5 & NL & H-area & 0.2 & 0.14 & No \\
\hline Case 5 & 2.5 & NL & F-area & 0.16 & 3.1 & No \\
\hline Case 6 & 2.5 & NL & H-area & 0.33 & 1.8 & No \\
\hline Case 7 & 2.5 & NL & F-area & 0.16 & 2.4 & No \\
\hline Case 8 & 2.5 & NL & H-area & 0.21 & 2.1 & No \\
\hline
\end{tabular}

* Light conditions during decomposition: NL - no light; DL - dirty light; CL - clean light

** The electrochemical corrosion rate average was taken of the final instantaneous corrosion rate measurement.

\subsection{IMPACTS ON GENERAL CORROSION RATE OF DEPOSITION TANK}

The general corrosion rate of the deposition tank would be expected to increase with direct contact from the ECC destruction loop effluent over the nominal rate of less than 1 mpy for current SRS waste chemistries [28] since the $\mathrm{pH}$ of these solution are lower than that of the high level waste. The data from both the 1 and $2.5 \mathrm{wt} \%$ OA corrosion testing at AREVA 
showed corrosion rates that were an order of magnitude greater. For the $2.5 \mathrm{wt} \% \mathrm{OA}$ solutions with the no-light condition for the destruction loop, the average rates were 8.4 and 13.6 mpy for the H-area and F-area sludge based effluents, respectively. The rates in the 1 wt\% OA solutions were slightly greater with average rates for a no light condition of 9.1 and 19.6 mpy for the H-area and F-area sludge based effluents, respectively. The corrosion rates for dirty and clean light conditions were lower, similar to the rates with $2.5 \mathrm{wt} \% \mathrm{OA}$. The higher corrosion rates measured in the 1\% OA-based effluents over those in 2.5\% OA-based effluents was surprising since the $2.5 \%$ based effluents would be expected to have more dissolved species. The reason for this difference is difficult to determine without more posttest chemical analysis to indicate specific test chemistries.

The electrochemical corrosion rates, which are instantaneous, give a snapshot of the corrosion at a point in time as opposed to the time-averaged weight-loss corrosion rates from immersion coupons. For both the uninhibited effluents, the electrochemical rates, which ranged from 1.9 to 24.7 mpy, were generally lower than those calculated by weight loss, although the ranges overlapped. The electrochemical corrosion rates showed that the rates decreased with time of exposure, which is attributed to the build up of corrosion products and oxides as observed on the samples after testing.

The corrosion of carbon steel in water with a $\mathrm{pH}$ of $5-9$ at $22{ }^{\circ} \mathrm{C}$ has a corrosion rate around 10 mpy [13]. When corrosion is controlled by the diffusion of oxygen, which would be the controlling mechanism for carbon steel in these uninhibited effluents, the corrosion rate approximately doubles for every $30{ }^{\circ} \mathrm{C}$ rise in temperature. The corrosion rate of water at 50 ${ }^{\circ} \mathrm{C}$, which is the test temperature, would be approximately 20 mpy [14]. The A537 corrosion rates observed in these effluents does not differ significantly from corrosion rates in water at these temperatures. The effect of secondary oxidizers or radicals formed during this process, therefore, did not have a significant effect on the A537 corrosion rate.

The difference in corrosion rates of uninhibited effluent with F-area and H-area sludge dissolution did not correlate with the chemistry parameters evaluated during the testing. Values of $\mathrm{pH}$, ORP and $\mathrm{Hg}$ concentrations were similar or had overlapping ranges. The Farea sludge on make up had a higher chloride concentration than $\mathrm{H}$-area sludge (1.73 versus $0.31 \mathrm{~g} / \mathrm{L}$ ) which may have contributed to the higher corrosion rate [15]. Chlorides are usually associated with pitting, although at these neutral $\mathrm{pH}$ values the thin oxide on the steel would be more susceptible to a general breakdown from the chlorides. The linear array of pits observed on these coupons is believed to be associated with the impurities in the A537 carbon steel, which acted as precursors for pitting.

Corrosion control measures and evaporation were all effective in lowering the corrosion rate of the destruction loop effluent. These rates for the most part were independent of sludge chemistry. The mixing of the effluent with a supernate heel high in hydroxide (5-6 M, case $1 \mathrm{~B}$ and $2 \mathrm{~B}$ ) dropped corrosion rates to the lowest value, approximately 0.2 mpy for either sludge type. This supernate chemistry was taken to be representative of tank farm chemistries. Slightly higher corrosion rates of 1-2 mpy were measured when the effluent was mixed with a supernate chemistry having a high nitrate $(2 \mathrm{M})$ concentration representative of Type III tanks (hydroxide concentration was 0.5-0.6 M). This rate will be a function of the 
volume ratio of the uninhibited effluent to the supernate. These low corrosion rates are considered excellent for industrial items, although rates less than $1 \mathrm{mpy}$ should be possible by reducing the uninhibited effluent volume.

A difference in corrosion rate was noted for sludge type when the effluent was hydroxide adjusted (cases 3 and 4). The $\mathrm{pH}$ of the effluent was adjusted to 12 prior to mixing with the nominal supernate chemistry. For $\mathrm{H}$-area sludge based effluents, the corrosion rates were approximately $0.2 \mathrm{mpy}$, similar to corrosion rates when mixed with the high hydroxide supernate. For the F-area sludge base effluents, the corrosion rates were approximately 1.2 mpy which were more similar to corrosion rates for the nominal supernate chemistry. There was no apparent reason for this difference since the $\mathrm{H}$ - and F-area sludge based effluents have performed similarly. If the representative supernate was used for the H-area testing, a lower corrosion rate would be expected.

For cases when the evaporator was used (cases 5-8), corrosion rates in solutions based on both types of sludges were quite low, approximately $0.2 \mathrm{mpy}$. The hydroxide addition did not affect the corrosion rate. The electrochemical corrosion rates were in good agreement with the weight loss data except for the evaporator cases where the weight loss corrosion rates were an order of magnitude lower than the electrochemical data. A small amount of pitting was found with $\mathrm{H}$-area based effluents although the pitting was associated with the few spots of localized breakdown and may, therefore, not be true growing pits.

\subsection{IMPACTS ON CORROSION PROCESS OF DEPOSITION TANK}

The corrosion of the carbon steel in the decomposition effluent for the two OA concentrations was dominated by anodic dissolution as shown in Figures 4.2-5 and 4.3-4. This dissolution is consistent with the observed rust and black corrosion products on the coupons. Although the corrosion products were not analyzed, the rust and black coloring is noted for ferric hydroxide $(\mathrm{FeOOH})$ and magnetite $\left(\mathrm{Fe}_{3} \mathrm{O}_{4}\right)$, respectively. Magnetite forms when oxygen is not readily available. This condition may have occurred in these tests because of the elevated test temperature and the lack of solution agitation. The ozone, which may be a source of oxygen, was not expected to be present in any significant concentration exiting the destruction loop.

The CPP scans in the uninhibited decomposition effluent were also noted to have a positive hysteresis in most cases. This positive hysteresis is an indication of pitting susceptibility. Both the immersion and electrochemical coupons were found to have pitted. Pits on the immersion coupons on average were less than 1 mil with a maximum pit depth of 1.5 mils being measured. Pit were found to grow between 65 and 288 hours, although the depths were still significantly smaller than the tank wall thickness ( 0.5 inch). The pit depths were not dependent on sludge chemistry since pit depths were similar for coupons exposed to both $\mathrm{H}$-area and F-area based uninhibited effluents. The pit formation is attributed to the chlorides that were present in the sludge at levels between 0.31 to $1.73 \mathrm{~g} / \mathrm{L}$ [15] and to the impurity in the material, as shown in Figure 4.2-4, acting as initiation sites. The pitting would not be expected to be a concern to the tank since they appear to be associated with material impurities and tank walls would have an oxidized surface. 
The corrosion control measures that were tested in this study were all effective in changing the corrosion of A537 from active dissolution to passivity. The A537 carbon steel displayed passive behavior with passive current densities generally in the range of $10^{-5}$ to $10^{-4} \mathrm{~A} / \mathrm{cm}^{2}$ as shown in Figures 4.4.1-3, 4.4.2-3, 4.4.3-3, and 4.4.4-3. In several cases, a positive hysteresis on the entire reverse scan was noted in the CPP scans, specifically for effluents mixed with the supernate with minimal inhibitor concentrations. This pitting susceptibility is associated with the uninhibited effluent:supernate volume ratio. The uninhibited effluent dilutes the inhibitor concentration while increasing the nitrate concentration. The ratio of 2:5 tested in this study is too high to maintain protection for the waste tanks.

Pitting was observed in most cases on the electrochemical coupons although pitting was not observed on immersion coupons, especially from solutions that were evaporated. The CPP scans for these cases showed a positive hysteresis only at electropositive potentials, so the pitting may be associated with the electrochemical test performance. If tests are run to too high a potential or too large a current, which takes it out of probable conditions that could occur in service, the oxide on the coupon surface is taken to a region of instability that would lead to pitting. A vertex current density of $0.1 \mathrm{~mA} / \mathrm{cm}^{2}$ is one rule-of-thumb used as the point of reversing the scan [13], although higher can be used as historically performed for HLW studies. Most of the CPP scans in this testing reversed at about $2 \mathrm{~mA} / \mathrm{cm}^{2}$, so pitting could be observed in the electrochemical test but not the immersion test. Pitting, therefore, would not be expected to occur in service for these cases. The use of the $2 \mathrm{~mA} / \mathrm{cm}^{2}$ vertex current density does not negate the data on passive current densities or the electrochemical corrosion rates, which were acquired prior to the vertex current density.

The anodic peak in the range of 0.2 to $0.4 \mathrm{~V}$ that was observed on the CPP scans for the corrosion control tests but not the uninhibited effluent from the destruction loop is believed to be associated with dissolution of ferrous oxalate that was present in the solids. Ferrous oxalate is not stable at higher $\mathrm{pH}$ values as shown by the iron-oxalic acid-water Pourbaix diagram in Figure 5.2-1 [16]. In the uninhibited effluent where the $\mathrm{pH}$ was generally between 7 and 8, any ferrous oxalate solids would not dissolve into solution. At the higher $\mathrm{pH}$, ferrous oxalate breaks down to ferrous and oxalate components. During the CPP scan, the ferrous hydroxide which is not in solution initially is oxidized to the ferric state [17]. If one test cell had more solids than another, the peak size would vary because of concentration differences in the solutions as was observed for the F-area based effluents shown in Figure 4.4.1-3.

These anodic peaks were generally not observed in the evaporator solutions. The higher $\mathrm{pH}$ of the evaporator solutions, in which higher OA concentrations were measured, would lead to oxidation of the ferrous ions and thereby not be electrochemically active. In these CPP scans, anodic peaks around $0.0 \mathrm{~V}$ were observed when hydroxide additions were made. These active to passive transition peaks are indicative of the formation of passive film on the steel surface that leads to lower passive current densities and indicate a protective oxide.

One concern at the start of testing was the impact of secondary oxidizers or radicals, which may be formed during the decomposition process. The OCP and instantaneous corrosion rate do not appear to support a negative effect of these species if they are present. During each 
batch exposure, these values followed typical pattern observed as a metal reaches a quasiequilibrium during corrosion. The OCP started at electronegative values and moved to more positive values over the course of the test $(-650 \mathrm{mV}$ to $-350 \mathrm{mV})$ indicative of the formation of oxides or corrosion products on the surface. Associated with this move in the OCP was a decrease in the corrosion rate over the exposure. Additionally CPP scans that were performed on new coupons exposed during the first batch (18 hours) and third batch (168 hours) of the uninhibited $\mathrm{H}$-area base effluents with $2.5 \%$ OA were very similar. If these short lived species were present, they had no impact greater than 18 hours.

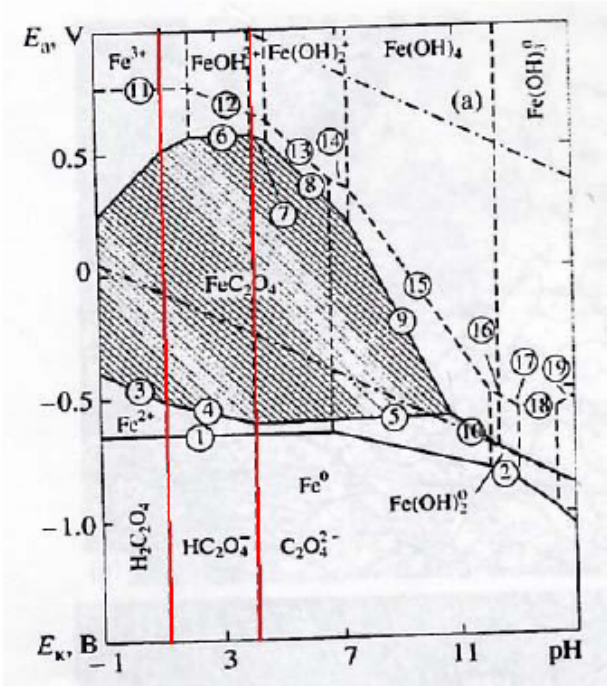

Figure 5.2-1 Iron-Oxalic Acid-Water Pourbaix Diagram [16].

\subsection{CONCLUSIONS}

The corrosion testing associated with the AREVA ECC-HST evaluated the corrosion susceptibility of A537 carbon steel and 304L stainless steel to the destruction loop effluent from the ECC process. The findings from this testing were as follows:

- Corrosion rates in uninhibited effluent from the destruction loop were an order of magnitude greater than those of inhibited waste, which measures less than $1 \mathrm{mpy}$.

- Corrosion rates in F-area based uninhibited effluents were greater than H-area based uninhibited effluents and may be associated with the higher chloride concentration of the F-area sludge simulant.

- Corrosion rates in 1\% OA-based uninhibited effluents were higher than those measured in 2.5\% OA-based uninhibited effluents.

- Pitting ( 1 mil) occurred in uninhibited effluent for both types of sludge. This increased corrosion susceptibility was associated with the presence of chlorides, the presence of impurities in the material, and the lack of a protective oxide. 
- Corrosion rates in effluent treated for corrosion control were generally less than 1 mpy, similar to inhibited waste, although pitting was found for effluent combined with low inhibitor supernate (0.5M hydroxide and $0.3 \mathrm{M}$ nitrite).

- Corrosion rates in effluent undergoing evaporation had lower corrosion rates than uninhibited effluent (weight-loss corrosion rates were similar to those for inhibited waste; instantaneous corrosion rates were 2-3 mpy).

- The lower corrosion rates with corrosion control options or evaporation were associated with the formation of a passive oxide on carbon steel.

\subsection{ACKNOWLEDGEMENTS}

The assistance of AREVA personnel, Sarah Evans, Yinhua (Daisy) Qi, Louis Steiglman, and Will Hix are gratefully acknowledged for their managing and conducting the experimental work reported here. Discussions with Bruce Wiersma during the analysis of the data were helpful in resolving unexpected results. The author is grateful for the contribution of Chris Martino with the scheduling of tasks associated with this work

\subsection{REFERENCES}

1. S. Dennis Jones, "Savannah River Enhanced Chemical Cleaning Sludge Simulant Demonstration” AREVA NP Inc. report \#51-9063140-000, October 9, 2007.

2. E. T. Ketusky, "Enhanced Chemical Cleaning (ECC) Hazardous Simulant Development \& Treatment Tank Corrosion Testing,” HLE-TTR-2009-116, Rev. 2, December 9, 2010.

3. E. T. Ketusky, "Path Forward: Enhanced Chemical Cleaning (ECC) Hazardous Simulant \& Real Waste Testing Functional Classification/Data Qualification,” SRR-LWE-201000182, Rev. 1, January 27, 2011.

4. Russell Eibling et al, “Task Technical and Quality Assurance Plan for Simulant Development, Production, and Corrosion Testing for Enhanced Chemical Cleaning," SRNL-RP-2009-01038, Revision 2, February 2011.

5. SRNL R\&D Direction, "Use of Gamry Electrochemical Test Equipment For Enhanced Chemical Cleaning Hazardous Simulant Testing - Task 2,” June 16, 2010

6. AREVA Document 03-9146825, "Chemical Applications Engineering Gamry ${ }^{\mathrm{TM}}$ System Operating Instructions for use in Enhanced Chemical Cleaning Hazardous Simulant Testing,” Revision 0, October 18, 2010.

7. J. I. Mickalonis, "Training Requirements for AREVA on Corrosion Testing in Support of ECC-HST,” SRNL-L7400-2010-00015 (SRR-LWE-2010-00291), November 29, 2010. 
8. Personal Property Loan Agreement \# 100325, May 17, 2010.

9. ASTM G1 - 2003, Standard Practice for Preparing, Cleaning, and Evaluating Corrosion Test Specimens, ASTM International, Conshocken, PA, 2010.

10. ASTM G2 - 89 (Reviewed 2010), Practice for Calculation of Corrosion Rates and Related Information from Electrochemical Measurements, ASTM International, Conshocken, PA, 2010.

11. ASTM G59 - 97 (Reviewed 2009), Standard Test Method for Conducting Potentiodynamic Polarization Resistance Measurements, ASTM International, Conshocken, PA, 2010.

12. ASTM G5 - 94 (Reviewed 2004), Standard Reference Test Method for Making Potentiostatic and Potentiodynamic Anodic Polarization Measurement, ASTM International, Conshocken, PA, 2010.

13. R. Winston Revie (ed), Ulhig's Corrosion Handbook, John Wiley \& Sons, New York, New York, 2000, p 536.

14. H. H. Uhlig, Corrosion and Corrosion Control, John Wiley \& Sons, New York, New York, 1971, p 97.

15. Russell E. Eibling, “Development of Hazardous Sludge Simulants for Enhanced Chemical Cleaning Tests,” SRNL-STI-2010-00170, April 2010.

16. S. N. Saltykov, “A Mechanism of the Anodic Dissolution of Armco Iron and High Strength Ferritic Cast Iron in an Oxalate Medium,” Protection of Metals, vol. 37(2), pp 186-191, 2001.

17. B. J. Wiersma and J. I. Mickalonis, "Electrochemical Studies on the Corrosion of Carbon Steel in Oxalic Acid Cleaning Solutions,” Corrosion2008, NACE International, Houston Texas.

18. AREVA Document 51-9162294-000, "Enhanced Chemical Cleaning Hazardous Simulant Testing Task 3 1-H Gamry Data, October 18, 2010

19. AREVA Document 51-9162294-000, "Enhanced Chemical Cleaning Hazardous Simulant Testing Task 3 1-F Gamry Data, October 18, 2010

20. AREVA Document 51-9162297-000, “Enhanced Chemical Cleaning Hazardous Simulant Testing Task 4 2-F Gamry Data, October 18, 2010

21. AREVA Document 51-9162295-000, "Enhanced Chemical Cleaning Hazardous Simulant Testing Task 4 2-H Gamry Data, October 18, 2010 
22. AREVA Document 51-9156351-001, “Test Results from Enhanced Chemical Cleaning Hazardous Simulant Testing Task 9, 11 A \& C, October 18, 2010

23. AREVA Document 51-9161597-000, “Test Results from Enhanced Chemical Cleaning Hazardous Simulant Testing Task 2, October 18, 2010

24. AREVA Document 51-9153288-000, "ECC-HST Task 3, 4, 9, 10, and 11 Report, October 18, 2010

25. E7 Manual, Conduct of Engineering and Technical Support Procedure Manual, Procedure 3.7, Qualification of Existing Data, Revision 4, July 1, 2004.

26. P. A. Schweitzer, Corrosion Resistance Tables, $3^{\text {rd }}$ Ed., Marcel Dekker, NY, NY, 1991.

27. ASTM G31 - 72 (Reapproved 2004), Standard Practice for Laboratory Immersion Corrosion Testing of Metals, ASTM International, Conshocken, PA, 2010.

28. B. J. Wiersma, "Estimation of High Level Waste (HLW) Tank Remaining Service Life," WSRC-TR-2005-00196, May 2005.

29. E. T. Ketusky, "Qualification of Enhanced Chemical Cleaning 1 wt\% Oxalic Acid Deposition Tank Key Test Parameters,” U-DQR-F-00003, August, 2011. 
APPENDIX I

Weight Losses and Corrosion Rates of Immersion Coupons

\begin{tabular}{|c|c|c|c|c|c|c|}
\hline $\begin{array}{c}\text { AREVA } \\
\text { Test \# }\end{array}$ & Coupon \# & $\begin{array}{c}\text { Pre-Test } \\
\text { Weight } \\
\text { (g) }\end{array}$ & $\begin{array}{c}\text { Post-Test } \\
\text { Weight } \\
\text { (g) }\end{array}$ & $\begin{array}{c}\text { Weight } \\
\text { Loss } \\
\text { (g) }\end{array}$ & $\begin{array}{c}\text { Test } \\
\text { Time } \\
\text { (hr) }\end{array}$ & $\begin{array}{c}\text { Corrosion } \\
\text { Rate } \\
(\mathrm{mpy})\end{array}$ \\
\hline F-NL-\#1 & A537CL1-33 & 33.98885 & 33.88225 & 0.1066 & 64.7 & 23.4 \\
\hline F-NL-\#3 & A537CL1-34 & 34.037 & 33.96505 & 0.0720 & 64.7 & 15.8 \\
\hline F-CL-\#1 & A537CL1-35 & 34.34975 & 34.29275 & 0.0570 & 65.2 & 12.4 \\
\hline F-CL-\#3 & A537CL1-36 & 34.05495 & 33.9984 & 0.0566 & 65.2 & 12.3 \\
\hline F-DL-\#1 & A537CL1-38 & 33.92 & 33.84515 & 0.0748 & 67.1 & 15.9 \\
\hline F-DL-\#3 & A537CL1-39 & 33.9511 & 33.88485 & 0.0662 & 67.1 & 14.0 \\
\hline H-NL-\#1 & A537CL1-40 & 34.08815 & 34.03365 & 0.0545 & 67.1 & 11.6 \\
\hline H-NL-\#3 & A537CL1-41 & 33.9932 & 33.9517 & 0.0415 & 67.1 & 8.8 \\
\hline H-CL-\#1 & A537CL1-42 & 34.0023 & 33.95545 & 0.0468 & 66.3 & 10.1 \\
\hline H-CL-\#3 & A537CL1-43 & 34.0373 & 33.99895 & 0.0384 & 66.3 & 8.2 \\
\hline H-DL-\#1 & A537CL1-44 & 34.15255 & 34.10815 & 0.0444 & 67.2 & 9.4 \\
\hline H-DL-\#3 & A537CL1-45 & 33.97625 & 33.9412 & 0.0351 & 67.2 & 7.4 \\
\hline $\begin{array}{l}\text { A-H-NL (Task } \\
\text { 11A) }\end{array}$ & A537CL1-46 & 34.0804 & 33.93605 & 0.1443 & 288 & 7.1 \\
\hline $\begin{array}{c}\text { A-H-NL (Task } \\
11 \mathrm{~A})\end{array}$ & A537CL1-47 & 34.1021 & 33.98135 & 0.1208 & 288 & 6.0 \\
\hline $\begin{array}{c}\text { A-H-NL (Task } \\
11 \mathrm{~A})\end{array}$ & A537CL1-48 & 33.7965 & 33.6744 & 0.1221 & 288 & 6.0 \\
\hline $\begin{array}{c}\text { A-H-NL (Task } \\
\text { 11C) }\end{array}$ & A537CL1-49 & 34.10275 & 34.06135 & 0.0414 & 73.8 & 8.0 \\
\hline $\begin{array}{c}\text { A-H-NL (Task } \\
11 \mathrm{C})\end{array}$ & A537CL1-50 & 34.1576 & 34.1123 & 0.0453 & 73.8 & 8.7 \\
\hline A-F-NL & A537CL1-51 & 34.37895 & 34.3108 & 0.0682 & 65.3 & 14.8 \\
\hline A-F-NL & A537CL1-52 & 34.15675 & 34.09995 & 0.0568 & 65.3 & 12.4 \\
\hline $1-\mathrm{F}$ & A537CL1-53 & 34.05675 & 34.0493 & 0.0074 & 218.8 & 0.5 \\
\hline $1-\mathrm{F}$ & A537CL1-54 & 34.14175 & 34.13725 & 0.0045 & 218.8 & 0.3 \\
\hline $1-\mathrm{F}$ & A537CL1-55 & 34.20055 & 34.19475 & 0.0058 & 218.8 & 0.4 \\
\hline $1-\mathrm{F}$ & A537CL1-56 & 34.12465 & 34.11865 & 0.0060 & 218.8 & 0.4 \\
\hline $1-\mathrm{F}$ & A537CL1-57 & 34.15625 & 34.15235 & 0.0039 & 218.8 & 0.3 \\
\hline $1-\mathrm{F}$ & A537CL1-58 & 34.19 & 34.1858 & 0.0042 & 218.8 & 0.3 \\
\hline $1-\mathrm{H}$ & A537CL1-59 & 34.0918 & 34.0876 & 0.0042 & 229 & 0.3 \\
\hline $1-\mathrm{H}$ & A537CL1-60 & 34.34555 & 34.3421 & 0.0035 & 229 & 0.2 \\
\hline $1-\mathrm{H}$ & A537CL1-61 & 33.9539 & 33.9496 & 0.0043 & 229 & 0.3 \\
\hline $1-\mathrm{H}$ & A537CL1-62 & \begin{tabular}{|l|}
33.8571 \\
\end{tabular} & 33.85295 & 0.0042 & 229 & 0.3 \\
\hline $1-\mathrm{H}$ & A537CL1-63 & 34.131 & 34.12755 & 0.0035 & 229 & 0.2 \\
\hline $1-\mathrm{H}$ & A537CL1-64 & 33.96685 & 33.9637 & 0.0031 & 229 & 0.2 \\
\hline $2-\mathrm{F}$ & A537CL1-65 & 34.1864 & 34.183 & 0.0034 & 290.2 & 0.2 \\
\hline $2-\mathrm{F}$ & A537CL1-66 & 34.09335 & 34.0901 & 0.0033 & 290.2 & 0.2 \\
\hline $2-\mathrm{F}$ & A537CL1-67 & 34.11805 & 34.1145 & 0.0035 & 290.2 & 0.2 \\
\hline $2-\mathrm{F}$ & A537CL1-68 & 34.21995 & 34.21715 & 0.0028 & 290.2 & 0.1 \\
\hline $2-\mathrm{H}$ & A537CL1-69 & 34.02365 & 34.0144 & 0.0093 & 281.5 & 0.5 \\
\hline $2-\mathrm{H}$ & A537CL1-70 & 34.08565 & 34.08195 & 0.0037 & 281.5 & 0.2 \\
\hline $2-\mathrm{H}$ & A537CL1-01 & 57.6745 & 57.67735 & -0.0029 & 281.5 & -0.1 \\
\hline $2-\mathrm{H}$ & A537CL1-02 & 57.58265 & 57.5784 & 0.0042 & 281.5 & 0.2 \\
\hline
\end{tabular}




\section{APPENDIX II}

Instantaneous Corrosion Rates of Electrochemical Coupons In Uninhibited Effluent

\begin{tabular}{|c|c|c|c|c|c|}
\hline \multirow[b]{2}{*}{ Test \# } & \multirow[b]{2}{*}{ Coupon \# } & \multicolumn{2}{|c|}{ Initial } & \multicolumn{2}{|c|}{ Final } \\
\hline & & OCP (mV) & $\begin{array}{c}\text { Corrosion } \\
\text { Rate (mpy) }\end{array}$ & OCP (mV) & $\begin{array}{r}\text { Corrosion } \\
\text { Rate (mpy) }\end{array}$ \\
\hline F-NL-1-\#1 & EC-A537-8 & -592 & 6.82 & -580 & 1.85 \\
\hline F-NL-2-\#1 & & -457 & 4.13 & -438 & 4.68 \\
\hline F-NL-3-\#1 & & -329 & 9.23 & -339 & 9.14 \\
\hline F-NL-1-\#3 & EC-A537-5 & -631 & 8.2 & -641 & 3.49 \\
\hline F-NL-2-\#3 & & -548 & 6.55 & -436 & 5.46 \\
\hline F-NL-3-\#3 & & -290 & 5.77 & -328 & 5.21 \\
\hline F-CL-1-\#1 & EC-A537-1 & -631 & 12.64 & -642 & 5.84 \\
\hline F-CL-2-\#1 & & -500 & 13.43 & -423 & 8.36 \\
\hline F-CL-3-\#1 & & -322 & 8.39 & -251 & 6.25 \\
\hline F-CL-1-\#3 & EC-A537-2 & -644 & 12.3 & -618 & 8 \\
\hline F-CL-2-\#3 & & -381 & 8.5 & -349 & 8.59 \\
\hline F-CL-3-\#3 & & -335 & 7.61 & -297 & 6.37 \\
\hline F-DL-1-\#1 & EC-A537-3 & -672 & 16.3 & -645 & 7.29 \\
\hline F-DL-2-\#1 & & -561 & 10.24 & -459 & 5.36 \\
\hline F-DL-3-\#1 & & -394 & 11.9 & -388 & 6.88 \\
\hline F-DL-1-\#3 & EC-A537-4 & $\begin{array}{l}-638 \\
\end{array}$ & 11.34 & $\begin{array}{l}-641 \\
\end{array}$ & 8.37 \\
\hline F-DL-2-\#3 & & -569 & 14.8 & -444 & 6.9 \\
\hline F-DL-3-\#3 & & -328 & 8.39 & -347 & 7.95 \\
\hline H-NL-1-\#1 & EC-A537-6 & -628 & 189.4 & -615 & 93 \\
\hline H-NL-2-\#1 & & -381 & 8.14 & -315 & 6.63 \\
\hline H-NL-3-\#1 & & -365 & 9.37 & -414 & 8.3 \\
\hline H-NL-1-\#3 & EC-A537-7 & -639 & 24.72 & -581 & 5.8 \\
\hline H-NL-2-\#3 & & -411 & 12.37 & -349 & 10.28 \\
\hline H-NL-3-\#3 & & -439 & 10.12 & -412 & 9.48 \\
\hline H-CL-1-\#1 & EC-A537-9 & ND & ND & ND & ND \\
\hline H-CL-2-\#1 & & -284 & 12.67 & -268 & 11.55 \\
\hline H-CL-3-\#1 & & ND & 11.24 & -352 & 11.3 \\
\hline H-CL-1-\#3 & EC-A537-10 & -618 & 16.98 & -306 & 2 \\
\hline H-CL-2-\#3 & & ND & ND & ND & ND \\
\hline H-CL-3-\#3 & EC-A537-15 & ND & 255.8 & -654 & 4.07 \\
\hline H-DL-1-\#1 & EC-A537-11 & -673 & 12.56 & -489 & 2.37 \\
\hline H-DL-2-\#1 & & -275 & 9.35 & -237 & 8 \\
\hline H-DL-3-\#1 & & -331 & 9.19 & -365 & 9.86 \\
\hline H-DL-1-\#3 & EC-A537-12 & -665 & 8.43 & -445 & 1.9 \\
\hline H-DL-2-\#3 & & -271 & 4.6 & -221 & 3.04 \\
\hline H-DL-3-\#3 & & -303 & 4.22 & -215 & 2.18 \\
\hline A-F-NL-1 \#1 & EC-A537-39 & -672 & 9.2 & -656 & 4.8 \\
\hline A- F-NL-2-\#1 & & -606 & 10 & -614 & 6.2 \\
\hline A-F-NL-3-\#1 & & -465 & 7.1 & -430 & 4.4 \\
\hline A-F-NL-1-\#2 & EC-A537-40 & -672 & 13.7 & -643 & 5 \\
\hline A-F-NL-2-\#2 & & -550 & 9.5 & -567 & 4.8 \\
\hline A-F-NL-3-\#2 & & -503 & 9.7 & -467 & 4.3 \\
\hline A-H-NL-1 \#1 & EC-A537-37 & -661 & 10.8 & -635 & 3.1 \\
\hline A- H-NL-2-\#1 & & -267 & 4.6 & -379 & 4.3 \\
\hline A-H-NL-3-\#1 & & ND & 8.1 & -661 & 4.5 \\
\hline A-H-NL-1-\#2 & EC-A537-38 & -682 & 8.1 & -641 & 3.7 \\
\hline A-H-NL-2-\#2 & & -421 & 6.7 & -356 & 4.1 \\
\hline A-H-NL-3-\#2 & & ND & 8.9 & -673 & 4.2 \\
\hline
\end{tabular}


SRNL-STI-2011-00428, REVISION 0

APPENDIX III

Instantaneous Corrosion Rates of Electrochemical Coupons In Effluent Treated for Corrosion Control

\begin{tabular}{|c|c|c|c|c|c|c|}
\hline \multirow[b]{2}{*}{ Case } & \multirow[b]{2}{*}{ Test \# } & \multirow[b]{2}{*}{ Coupon \# } & \multicolumn{2}{|c|}{ Initial } & \multicolumn{2}{|c|}{ Final } \\
\hline & & & $\begin{array}{l}\text { OCP } \\
(\mathrm{mV})\end{array}$ & $\begin{array}{c}\text { Corrosion } \\
\text { Rate (mpy) }\end{array}$ & $\begin{array}{l}\text { OCP } \\
(\mathrm{mV})\end{array}$ & $\begin{array}{c}\text { Corrosion } \\
\text { Rate (mpy) }\end{array}$ \\
\hline \multirow[t]{3}{*}{$2 \mathrm{~A}$} & 1-H-1 \#1 & EC-A537-22 & -183 & 5.67 & -282 & 2.56 \\
\hline & 1-H-2 \#1 & & -103 & 2.5 & -96 & 1.5 \\
\hline & 1-H-3-\#1 & & -85 & 1.7 & -99 & 1.48 \\
\hline \multirow[t]{3}{*}{$2 \mathrm{~A}$} & 1-H-1 \#4 & EC-A537-23 & -90 & 0.33 & -84 & 0.15 \\
\hline & 1-H-2 \#4 & & 19 & 0.07 & -55 & 0.15 \\
\hline & 1-H-3-\#4 & & -134 & 5.24 & -99 & 0.88 \\
\hline \multirow[t]{3}{*}{$2 \mathrm{~B}$} & 1-H-1 \#2 & EC-A537-24 & -165 & 0.8 & -140 & 0.2 \\
\hline & $1-\mathrm{H}-2$ \#2 & & -128 & 0.32 & -131 & 0.24 \\
\hline & 1-H-3-\#2 & & -114 & 0.5 & -120 & 0.12 \\
\hline \multirow[t]{3}{*}{$2 \mathrm{~B}$} & 1-H-1 \#5 & EC-A537-25 & -205 & 0.6 & -154 & 0.29 \\
\hline & $1-\mathrm{H}-2$ \#5 & & -156 & 0.97 & -148 & 0.4 \\
\hline & 1-H-3-\#5 & & -134 & 0.57 & -142 & 0.19 \\
\hline \multirow[t]{3}{*}{4} & 1-H-1 \#3 & EC-A537-26 & -152 & 0.6 & -118 & 0.15 \\
\hline & 1-H-2 \#3 & & -73 & 0.11 & -94 & 0.15 \\
\hline & $1-\mathrm{H}-3$ \#3 & & -98 & 0.21 & -94 & 0.11 \\
\hline \multirow[t]{3}{*}{4} & 1-H-1 \#6 & EC-A537-27 & -156 & 0.6 & -119 & 0.17 \\
\hline & 1-H-2 \#6 & & -94 & 0.19 & -80 & 0.17 \\
\hline & $1-\mathrm{H}-3$ \#6 & & -103 & 0.23 & -96 & 0.16 \\
\hline \multirow[t]{3}{*}{$1 \mathrm{~A}$} & 1-F-1 \#1 & EC-A537-16 & -117 & 4.68 & -113 & 0.11 \\
\hline & $1-\mathrm{F}-2$ \#1 & & -137 & 0.65 & -133 & 1.31 \\
\hline & 1-F-3-\#1 & & -113 & 1.36 & -103 & 0.66 \\
\hline \multirow[t]{3}{*}{$1 \mathrm{~A}$} & 1-F-1 \#4 & EC-A537-17 & -113 & 1.33 & -281 & 4.79 \\
\hline & $1-\mathrm{F}-2$ \#4 & & -141 & 3.8 & -122 & 2.8 \\
\hline & $1-\mathrm{F}-3-\# 4$ & & -114 & 4.04 & -109 & 2.87 \\
\hline \multirow[t]{3}{*}{$1 \mathrm{~B}$} & 1-F-1 \#2 & EC-A537-18 & -374 & 0.31 & -263 & 0.28 \\
\hline & $1-\mathrm{F}-2$ \#2 & & -194 & 0.48 & -190 & 0.82 \\
\hline & 1-F-3-\#2 & & -160 & 1.26 & -144 & 0.13 \\
\hline \multirow[t]{3}{*}{$1 \mathrm{~B}$} & 1-F-1 \#5 & EC-A537-19 & -223 & ND & -141 & ND \\
\hline & $1-\mathrm{F}-2$ \#5 & & -165 & 0.22 & -140 & 0.17 \\
\hline & 1-F-3-\#5 & & -119 & 0.17 & -92 & 0.25 \\
\hline \multirow[t]{3}{*}{3} & 1-F-1 \#3 & EC-A537-20 & -112 & 0.59 & -268 & 3.31 \\
\hline & $1-\mathrm{F}-2$ \#3 & & -117 & 4.1 & -111 & 3.2 \\
\hline & $1-\mathrm{F}-3$ \#3 & & -108 & 2.2 & -119 & 1.86 \\
\hline \multirow[t]{2}{*}{3} & 1-F-1 \#6 & EC-A537-21 & -118 & ND & -303 & ND \\
\hline & 1-F-2 \#6 & & -136 & ND & ND & ND \\
\hline 3 & $1-\mathrm{F}-3$ \#6 & EC-A537-36 & -127 & 0.98 & -118 & 0.5 \\
\hline
\end{tabular}


SRNL-STI-2011-00428, REVISION 0

APPENDIX III continued

Instantaneous Corrosion Rates of Electrochemical Coupons In Effluent Treated for Corrosion Control

\begin{tabular}{|c|c|c|c|c|c|c|}
\hline \multirow[b]{2}{*}{ Case } & \multirow[b]{2}{*}{ Test \# } & \multirow[b]{2}{*}{ Coupon \# } & \multicolumn{2}{|c|}{ Initial } & \multicolumn{2}{|c|}{ Final } \\
\hline & & & $\begin{array}{l}\text { OCP } \\
(\mathrm{mV})\end{array}$ & $\begin{array}{c}\text { Corrosion } \\
\text { Rate (mpy) }\end{array}$ & $\begin{array}{l}\text { OCP } \\
(\mathrm{mV})\end{array}$ & $\begin{array}{c}\text { Corrosion } \\
\text { Rate (mpy) }\end{array}$ \\
\hline \multirow[t]{3}{*}{6} & 2-H-1 \#4 & EC-A537-32 & -249 & ND & -275 & ND \\
\hline & 2-H-2 \#4 & & -268 & ND & -167 & ND \\
\hline & 2-H-3-\#4 & & -209 & 2.52 & -89 & 2.6 \\
\hline \multirow[t]{3}{*}{6} & 2-H-1 \#5 & EC-A537-33 & -239 & ND & -298 & ND \\
\hline & $2-\mathrm{H}-2$ \#5 & EC-A537-38 & -112 & ND & -118 & ND \\
\hline & 2-H-3-\#5 & & -130 & 1.42 & -84 & 1 \\
\hline \multirow[t]{3}{*}{8} & 2-H-1 \#3 & EC-A537-37 & -133 & 0.66 & -193 & 2.9 \\
\hline & $2-\mathrm{H}-2$ \#3 & & -154 & 4.1 & -118 & 2.6 \\
\hline & 2-H-3-\#3 & & -98 & 3.22 & -92 & 2.8 \\
\hline \multirow[t]{3}{*}{8} & 2-H-1 \#6 & EC-A537-34 & -145 & 0.57 & -141 & 2.2 \\
\hline & $2-\mathrm{H}-2$ \#6 & & -115 & 1.6 & -140 & 1.6 \\
\hline & $2-\mathrm{H}-3-\# 6$ & & -102 & 3.03 & -96 & 1.4 \\
\hline \multirow[t]{3}{*}{5} & 2-F-1 \#1 & EC-A537-28 & -238 & 3 & -270 & 2.8 \\
\hline & 2-F-2 \#1 & & -160 & 3.2 & -98 & 6 \\
\hline & $2-F-3 \# 1$ & & -140 & 3.48 & -100 & 2.8 \\
\hline \multirow[t]{3}{*}{5} & 2-F-1 \#4 & EC-A537-29 & ND & ND & -141 & 3.6 \\
\hline & 2-F-2 \#4 & EC-A537-35 & -198 & 1.4 & -210 & 5.7 \\
\hline & $2-\mathrm{F}-3$ \#4 & & -191 & 4.25 & -124 & 3.4 \\
\hline \multirow[t]{3}{*}{7} & 2-F-1 \#2 & EC-A537-30 & -111 & 1.4 & -327 & 5.5 \\
\hline & 2-F-2 \#2 & & -268 & 5.4 & -89 & 5.6 \\
\hline & 2-F-3-\#2 & & -150 & 3.75 & -100 & 3.1 \\
\hline \multirow[t]{3}{*}{7} & 2-F-1 \#5 & EC-A537-31 & -76 & 1.7 & -133 & 1.1 \\
\hline & 2-F-2 \#5 & & -148 & 7.6 & -172 & 2.7 \\
\hline & 2-F-3-\#5 & & -210 & 4.75 & -122 & 1.62 \\
\hline
\end{tabular}

